\title{
MEMES EN INSTAGRAM: UN ESTUDIO DE CASO DE CUENTAS DEDICADAS A LA PRODUCCIÓN Y CIRCULACIÓN DE ESTAS NARRATIVAS CONTEMPORÁNEAS
}

\author{
Dra. Bianca Racioppe \\ FPyCS-UNLP, La Plata, Argentina \\ bianca_racioppe@yahoo.com.ar \\ ORCID iD: https://orcid.org/0000-0002-0670-3300 \\ Lic. Julieta Párraga \\ FPyCS-UNLP, La Plata, Argentina \\ parraga.julieta@gmail.com \\ ORCID iD: https://orcid.org/0000-0002-0735-5360
}

Recibido el 22 de julio de 2019

Aceptado el 22 de abril de 2020

\section{Resumen}

Este artículo se enmarca en un proyecto de investigación desarrollado en la Facultad de Periodismo y Comunicación Social de la UNLP ${ }^{1}$ que tiene como principal objetivo identificar y analizar narrativas, estéticas y políticas en el escenario de la convergencia tecnológica. En este contexto, el meme emerge como una de esas narrativas recurrentes de los espacios digitales, por lo que este trabajo contribuye a abordar parte de la problemática que plantea el proyecto de investigación.

Para este artículo se exploró la red social digital Instagram como espacio de producción y circulación de memes, a los que se considera como una narrativa humorística contemporánea que, si bien se vincula a narrativas previas como el grafiti o el esténcil, se potencia en los escenarios digitales.

Se partió de la realización de una encuesta a administradores/as de cuentas de Instagram destinadas principalmente a la producción y circulación de memes. Luego, se pusieron en relación esas respuestas con un análisis de los memes que publican y de los vínculos que se dan entre las diferentes cuentas.

La indagación se posicionó, teórica y metodológicamente, en los Estudios Culturales. En este sentido, el análisis de las encuestas y de los memes se realizó teniendo en cuenta las lógicas de producción a partir de los siguientes núcleos: temporalidades de la producción, concepciones respecto de la originalidad/propiedad, conformación de redes de vínculos y estrategias de monetización.

Palabras clave: Redes sociales digitales, memes, lógicas de producción.

\footnotetext{
1 El proyecto es el PPID "Convergencia digital y rol del Estado. Análisis y abordajes en tiempos de desregulaciones" que dirige Martín González Frígoli y del que las autoras de este artículo forman parte.
} 


\title{
MEMES ON INSTAGRAM: A CASE STUDY OF ACCOUNTS DEDICATED TO THE PRODUCTION AND CIRCULATION OF THESE CONTEMPORARY NARRATIVES
}

\begin{abstract}
This article is part of a research project developed at the Faculty of Journalism and Social Communication of the UNLP whose main objective is to identify and analyze narratives, aesthetics and policies in the scenario of technological convergence. In this context, the meme emerges as one of those recurring narratives of digital spaces, so this work contributes to addressing part of the problem posed by the research project.

For this article, Instagram was explored as a space for the production and circulation of memes, which are considered as a contemporary humorous narrative that, although linked to previous narratives such as graffiti or stencil, is boosted in the digital scenarios.

The research began with a survey to Instagram users whose accounts are primarily dedicated to the production and circulation of memes. Then, these answers were related to an analysis of the memes that the different accounts publish and the links that exist between them.

The investigation was theoretically and methodologically based in the Cultural Studies. The analysis was carried out taking into account the following categories: temporalities of production, conceptions of originality/ownership, conformation of networks between accounts and monetization strategies.
\end{abstract}

Keywords: Digital social networks, memes, modes of production. 


\section{Introducción}

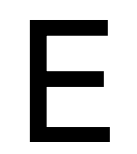

ste trabajo constituye una primera aproximación a un grupo de usuarios/as que publican memes en redes sociales digitales, tomando como casos de análisis cuentas de Instagram. Se eligió específicamente esta red social digital - aunque los memes circulan también por Twitter, Facebook y por servicios de mensajería como Whatsapp - porque es en la que se encontraron mayor cantidad de cuentas destinadas a la producción de memes.

Otro aspecto que se consideró al momento de elegir Instagram para realizar el estudio de casos fue que, según un análisis publicado por Hootsuite y We are social (2019), en Argentina Instagram ocupa el cuarto lugar entre las plataformas más usadas, luego de YouTube, Facebook y Whatsapp. En este primer acercamiento a la problemática descartamos Whatsapp porque, aunque permite la conformación de grupos y algunos se crean para circular memes, el modo de vinculación es diferente: se debe acceder a un enlace para sumarse y las personas que administran deben aceptar a cada integrante. Nos interesaba analizar plataformas que no requieran necesariamente de aprobación por parte de quienes administran. Por otro lado, no consideramos Facebook porque cada vez reúne a menos población joven y presenta menos actividad en sus cuentas. Según un estudio de Carrier (2019), las personas entre 18 y 30 años utilizan principalmente Instagram que, además, es la red social digital que más creció (en número de cuentas) en los últimos años.

Si bien en un principio consideramos incluir Twitter, notamos que muchas de las cuentas que comparten memes en esa red social digital están también en Instagram. Además, Twitter tiene un bajo porcentaje de uso en Argentina (según el informe de Carrier y Asociados sólo alcanza el 37\% de la población con acceso a Internet).

La aproximación al referente empírico se desarrolló en tres instancias. La primera consistió en un reconocimiento de cuentas de Instagram que tuvieran como uno de sus principales contenidos a los memes. En un segundo momento se formuló una encuesta que se distribuyó entre 40 cuentas de Instagram que habían sido identificadas en la primera etapa. Se obtuvieron 23 respuestas que posibilitaron focalizar en el tercer momento de aproximación al referente empírico: la articulación de las encuestas con el seguimiento de esas cuentas de Instagram desde la perspectiva de la etnografía virtual (Hine, 2004) o de la Netnography (Kozinets, 2010).

El abordaje se focalizó en las lógicas de producción a partir de indagar acerca de los momentos que destinan a la elaboración de memes, las concepciones que tienen respecto de la originalidad/propiedad, los modos en que conforman redes de vínculos y las estrategias de monetización. 
Si bien el término "meme" -como otros del campo de lo tecnológico- se vincula a una idea de replicación viral, este artículo se propuso conceptualizarlo desde la mirada de los Estudios Culturales. Para esto se retomaron los trabajos en los que Raymond Williams $(1992,2011)$ define lo tecnológico, la perspectiva de la comunicación de Jesús Martín-Barbero (1991) y la definición sobre narrativas mediáticas de Omar Rincón (2006, 2017).

\section{Qué entendemos por memes y cómo podemos pensarlos desde los Estudios Culturales}

Consideramos importante establecer nuestra postura en relación a lo que se entiende por meme para desplazarlo del lugar de una réplica viral y colocarlo, siguiendo la perspectiva de los estudios culturales (Martín-Barbero, 1991; Williams, 1992, 2011), en el entramado de los procesos socio-culturales. Como señalábamos antes, gran parte de los conceptos que utilizamos para referirnos al mundo de Internet proviene del estudio de ciencias como la biología y la ecología. Esto no es casual, ya que uno de los principales referentes del campo de lo digital es Marshall McLuhan al que se ubica como figura central de la perspectiva de la "Ecología de los medios" (Scolari, 2010). La propuesta de McLuhan (1996) de analizar los medios como especies dentro de un ecosistema es una de las más retomadas en el campo de la comunicación digital. Si bien, y tal como señala Scolari (2010), McLuhan nunca usó este término; sus categorías han sido recuperadas por esta perspectiva que piensa a Internet como un nuevo estadío en la evolución mediática. Así, referentes del campo como Henry Jenkins (2008); Jenkins, Ford y Green (2015); Carlos Scolari (2008, 2010); Roger Silverstone (2004), entre otros/as han retomado esta perspectiva sistémica, aunque vinculándola con una mirada constructivista. Scolari (2008) desarrolla, incluso, un planteo desde las hipermediaciones en el que articula la teoría de Martín-Barbero (1991) con el análisis de la Escuela de Toronto, cuyos principales referentes son Harold Innis y Marshall McLuhan.

En este marco, consideramos que es necesario desprendernos de la carga biologicista de ciertos conceptos utilizados y naturalizados en el campo de la comunicación digital. Reconocemos que no es el primer momento teórico en el que desde la comunicación usamos categorías vinculadas a lo natural para explicar procesos que son sociales. Esta apropiación de conceptos parece fundarse en el eterno complejo de "hermana menor" que las ciencias sociales guardan respecto de las naturales y de las exactas. Pero también puede relacionarse con el hecho del origen vinculado a la programación y a la informática que tuvieron los estudios sobre Internet. Palabras como virus, gusanos, especies, árboles, ratón, nube, replicante, meme son ejemplos de esa reutilización de conceptos. El problema de esta transpolación suele ser que intenta transparentar procesos sociales equiparándolos a procesos de la naturaleza. Lo que señalamos es lo que ya criticaban Martín-Barbero (1991), Héctor Schmucler (1984) y Armand Mattelart (1996) cuando cuestionaban el uso del paradigma informacional, proveniente de la ingeniería, para hablar de la comunicación. 
De hecho, la crítica a algunos de estos conceptos proviene de autores que retoman el paradigma sistémico de McLuhan. Por ejemplo, Jenkins, Ford y Green (2015) critican los conceptos de virus y viralización por considerarlos articulados a la concepción del receptor pasivo, un receptor que sería simplemente un huésped y no un agente de la circulación de los mensajes.

En el campo de la comunicación se considera que el origen del concepto "meme" se encuentra en el libro El gen egoísta del biólogo Richard Dawkins. El autor utiliza la palabra "meme" como abreviatura de mímeme porque quería una sonoridad similar a la de gen (1989: 1010). Así, para Dawkins:

"Ejemplos de memes son: tonadas o sones, ideas, consignas, modas en cuanto a vestimenta, formas de construir vasijas o construir arcos. Al igual que los genes se propagan en un acervo génico al saltar de un cuerpo a otro mediante los espermatozoides o los óvulos, así los memes se propagan en el acervo de memes al saltar de un cerebro a otro mediante un proceso que, considerado en su sentido más amplio, puede llamarse imitación". (1989: 1011)

Pero el mismo autor se sorprendió de cómo ese concepto había sido retomado en el campo de lo social. En una nota de la segunda edición del libro, Dawkins (1989: 1694) señala que no esperaba que el capítulo referido a los memes como agentes replicadores de la cultura alcanzara tal trascendencia porque con su libro él no buscaba hacer un aporte a la cultura, sino a la biología. Sin embargo, el término se transpoló a las ciencias sociales ya desde la década de 1980 y, actualmente, ha cobrado nueva fuerza al ser utilizado para definir determinados materiales que circulan por las redes sociales digitales. En este sentido, Pérez Salazar (2017) escribió un libro acerca de la circulación de memes en Internet en el que recupera estos orígenes del concepto y realiza, además, una genealogía en el campo de lo social. Pérez Salazar retoma la definición que da Dawkins y señala que un meme es "cualquier unidad cultural que es replicada" (2017: 6), por lo tanto, los memes existen desde antes de Internet. Algo similar plantea García Huerta (2014) cuando analiza grafitis y pintadas sencillas que se replicaban en diferentes paredes y cuyo origen no era del todo claro. En este punto aparece una pregunta que consideramos central: ¿Cómo se entienden la originalidad y las autorías en el caso de los memes? Cuando pensamos en los modos de circulación cultural previos al desarrollo de la imprenta, las autorías se vuelven difusas. La oralidad posibilitaba, al mismo tiempo, la réplica y la transformación. Los cuentos, las canciones, los relatos sufrían pequeñas mutaciones en las distintas regiones en las que se contaban. La imprenta, en cambio, posibilitó la copia exacta y transformó el modo de transmitir la herencia cultural (Thompson, 1998: 25). En el meme que circula en Internet emerge ese sentido difuso de la autoría -ésta es una de las categorías que tuvimos en cuenta para nuestro análisis-.

Si bien, como se explicaba antes, el término meme suele asociarse a la imitación, a la réplica; en este artículo queremos pensarlo más allá de estas ideas. Así como 
coincidimos con Jenkins, Ford y Green (2015) cuando critican el concepto de viralización, consideramos que pensar al meme sólo como replicante es limitar los sentidos de lo comunicacional a la transmisión de información. Por eso, y siguiendo a Nicolas Bourriaud (2007), consideramos que el simple hecho de colocar un objeto en otros contextos resignifica a ese objeto y, por lo tanto, lo convierte en algo-otro. En esta línea también va la teoría de Pérez Salazar (2017: 4) que considera, incluso, a La Gioconda como meme.

El problema que presenta esta definición es que es tan amplia que deja de tener utilidad analítica porque cualquier forma de circulación cultural podría ser interpretada como un meme. Por eso, una de las preguntas que recorre el trabajo de Pérez Salazar es "¿Cuál es la unidad mínima que nos permite hablar de un meme?" (2017: 19).

No es este desglose el que nos interesa -un ejercicio más pertinente al campo de la lingüística-, sino rastrear algunas características recurrentes en los modos de narrar en Internet que suelen agruparse bajo la categoría de meme. Entonces, a partir de esto podemos señalar que para este artículo el meme se entiende como una narrativa humorística que se nutre de los códigos compartidos, que circula en el espacio de Internet, aunque abreva en narrativas previas en las que la identificación del origen o de la autoría no es central, y que se asienta en la lógica de derivación y variación, más que en la imitación o la réplica. A partir de los casos de análisis intentamos aportar a esta caracterización poniendo el foco en los sentidos que los y las administradores/as de las cuentas le otorgan a los momentos de producción, a la originalidad, a las redes de vínculos y a las estrategias de monetización.

\section{En busca del perfil: edades, profesiones, momentos, expectativas y recursos}

Como señalamos antes, enviamos la encuesta a 40 cuentas de Instagram y obtuvimos 23 respuestas. La encuesta apuntaba a conocer lógicas de producción de los memes: recursos utilizados, fuentes de esos recursos; pero también motivaciones y expectativas. Queríamos recabar algunos indicadores que nos permitieran trazar un perfil de las personas que producen esos memes y sus porqués. Danna Chiarenza, asesora en estrategias para marcas y proyectos, asegura que toda propuesta en redes no sólo debe tener un qué y un cómo, sino también un porqué; es decir una motivación que hay que compartir con los/as seguidores/as (Chiarenza, 2019) ¿Qué es lo que motiva a abrir una cuenta en redes para crear y compartir memes? ¿Qué expectativas entran en juego? ¿Es una búsqueda de los 15 minutos de fama que proponía Andy Warhol? ¿Cómo se vinculan estos memes con las lógicas de la industria del entretenimiento? Claramente no vamos a poder responder en forma completa ninguna de estas grandes preguntas; pero plantearnos estas inquietudes nos llevó a preguntarnos quiénes son los sujetos que producen y comparten esos memes. 
La mayoría de las cuentas que respondieron la encuesta son sostenidas por estudiantes universitarios/as de entre 18 y 23 años (11 se ubican en esta categoría), también hay algunas cuentas creadas por estudiantes de escuela secundaria de entre 14 y 17 años ( 3 respuestas indican esa franja de edad). Cuatro de las cuentas analizadas fueron creadas por jóvenes adultos/as (entre los 24 y los 32 años) que, en cierta forma, tienen una profesión vinculada a los medios: marketing, producción de televisión, músicos/as, comunicadores/as. Las 5 cuentas restantes son administradas por personas que desarrollan trabajos que no están directamente vinculados con la producción de contenidos para Internet (comerciantes, empleados/as, profesionales de la salud, cocineros/as) y el rango etario de este grupo va de los 18 a los 30 años.

Un dato interesante es que 19 cuentas consignaron que crean los memes principalmente en su "tiempo libre", 2 aclararon que los hacen en el momento en el que tienen la idea y esta inspiración puede llegar mientras estudian o trabajan. Sólo 2 de las cuentas respondieron que tenían horas dedicadas especialmente a la creación de memes y que lo consideraban parte de sus tareas profesionales. Una de las que dio esta respuesta es manejada por un grupo o colectivo que, además, se dedica al marketing. El dato de cómo perciben el tiempo que le destinan a la creación de memes (si como ocio o como trabajo) es relevante para pensar la producción de contenidos en Internet desde una idea profesionalizante, que no la reduce a un pasatiempo.

Respecto a si la administración de la cuenta era grupal o individual, de las 23 respuestas sólo en 4 casos se indicó que eran un grupo detrás del usuario de redes. Las 19 cuentas restantes son manejadas por una sola persona. Esto no quiere decir que no se generen redes y vínculos entre las distintas cuentas -un aspecto que analizaremos más adelante-, sino que son administradas individualmente.

En relación a los recursos que más utilizan al momento de crear los memes, todas las cuentas respondieron que usan imágenes y textos; sólo 16 cuentas contestaron que además usan videos y sólo 8 mencionaron los collages y los dibujos. Estas respuestas se corresponden con los datos obtenidos del seguimiento en Instagram, ya que durante el trabajo etnográfico identificamos que el modo más generalizado para construir memes es el que García Huerta (2014: 3) denomina "imágenes macro". Las imágenes se obtienen de bancos de Internet, de capturas de programas de televisión, de series, de películas y también de las mismas redes sociales digitales; luego se les agregan textos que anclan los sentidos. En la mayoría de los casos los/as administradores/as no indagan si esos recursos (imágenes, videos, dibujos) están sujetos a Copyright. Sobre este aspecto volveremos en un próximo apartado. 


\section{El tiempo en Internet: entre el entretenimiento y el trabajo}

Decíamos que los porqués son importantes al momento de desarrollar un proyecto que se extienda en el tiempo, que perdure. Si bien los pasatiempos pueden sostenerse, Internet se caracteriza por la transformación constante: las plataformas cambian, las narrativas mutan. En este contexto, la motivación de las cuentas consultadas oscila entre el propósito de divertir y la búsqueda de una estrategia de posicionamiento en Internet que se amplíe más allá de la producción de memes.

A partir del análisis de las encuestas se identificó que una de las principales motivaciones es la búsqueda de entretener a las personas que siguen la cuenta, de transitar situaciones cotidianas a través del humor. En un caso, incluso, señalaron la importancia de crear conciencia sobre ciertos hechos a través de una propuesta cómica.

Hemos observado que, en algunas ocasiones, los y las memeros/as (Valeri, 2019) ${ }^{2}$ producen contenidos vinculados a las agendas sociales, políticas y mediáticas con el objetivo de incidir o aportar reflexiones en la conversación pública. En este sentido, el generador de contenido @elalesicumbiaok dijo: "A veces intento que a través de un meme se tome en serio tal cosa" (Véase imagen 1) y, en la misma línea, desde la cuenta de @gatitesproletaries comentaron que se busca "una contracultura de memes con conciencia de clase" (Véase imagen 2).

\footnotetext{
2 Tomamos este término de los/as productores/as de memes que se nombran a sí mismos/as de esta manera. Por ejemplo @n3neca, en una entrevista que le hizo Ariel Valeri para la revista digital ADM, se autodefine como "feminista, memera e instagramer".
} 
Fuente: Instagram @elalesicumbiaok. Recuperada el 10/06/2019

elalesicumbiaok

:lasheando que me voy a dar un / el hijo de recontra mil gustito este mes cuando cobre puta de Mauricio Macri
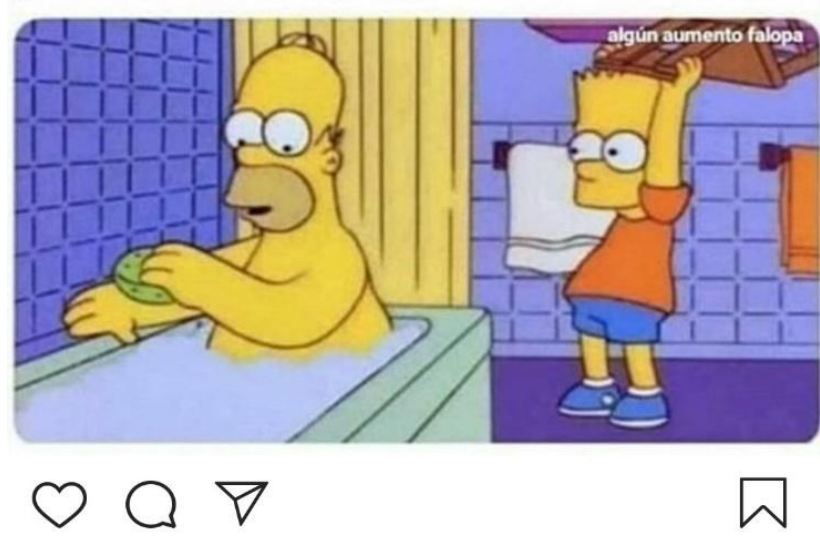

(3) gusta a andrescugat y $\mathbf{3 1 . 1 0 3}$ más

elalesicumbiaok Jajajaja gustito = comprar una leche la Serenisima

Ver los 355 comentarios

5 ros ahril - Vartradunnión

Imagen 1. Imagen de la cuenta de Instagram de @elalesicumbiaok.

Fuente: Instagram @gatitesproletaries. Recuperada el 10/06/2019

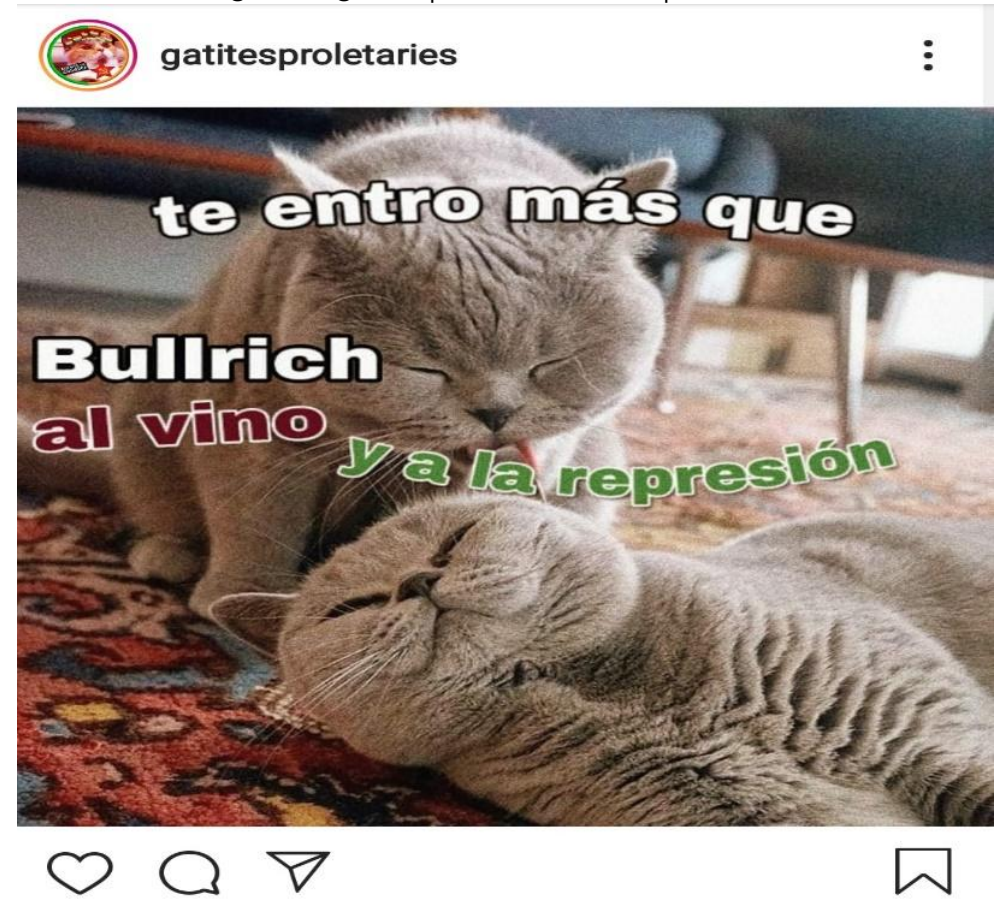

Imagen 2. Imagen de la cuenta de Instagram de @gatitesproletaries. 
El humor es una de las formas de narrar de la industria del entretenimiento (Rincón, 2006). Pero el arte -entendido como praxis (Gimpel, 1979; Bürger, 2000; Thornton, 2009), como aquel que se vincula a la experiencia de vida, a lo cotidiano- también busca, muchas veces, interpelar a través del humor con el objetivo de transformar situaciones. No es propósito de este artículo abordar el ya remanido debate entre las posturas que pretenden separar el entretenimiento (amusement) de la producción artística y aquellas que consideran que las Industrias Culturales y las Instituciones artísticas están entrelazadas. Posicionadas desde la comunicación/cultura, coincidimos con las posturas que consideran que el entretenimiento es un propósito válido de las prácticas artísticas y que aquellas miradas que lo sitúan en un lugar de inferioridad desconocen los modos en que los sujetos contemporáneos se vinculan con los relatos, desconocen que, como sostiene Omar Rincón, los medios de comunicación son "máquinas narrativas" (2006: 20).

En este mismo sentido, consideramos importante señalar la perspectiva capitalista que define al tiempo del entretenimiento como opuesto al del trabajo. Esto, a su vez, se liga al imaginario de que el tiempo en las redes sociales digitales es un tiempo desperdiciado. Para profundizar en estas representaciones, una serie de preguntas de la encuesta tuvo como propósito indagar en torno a los momentos de producción de memes. Se partió de la prenoción de que los/as realizadores/as de memes iban a focalizar en la separación entre tiempo productivo y tiempo de ocio e iban a ubicar a su trabajo de creación de memes en aquellos momentos considerados como no productivos, momentos de esparcimiento o pasatiempo. Aunque en 21 de las 23 respuestas obtenidas se afirma que principalmente crean los memes en "el tiempo libre", muchas de estas respuestas se combinan con expectativas positivas respecto de que los memes sean una instancia que les permita en el futuro producir contenidos para Internet (no necesariamente memes) como una forma de trabajo remunerado.

Esa es una expectativa a largo plazo, la proyección a corto plazo es que los memes que crean gusten, circulen, obtengan comentarios y eso redunde en la cantidad de seguidores/as y en la generación de un vínculo con la cuenta y su(s) responsable(s) para que luego pueda ser capitalizado - no necesariamente de manera económica - en otros proyectos. Por lo tanto, a la pretensión de entretener se suma la idea de generar contenidos que sean reconocidos.

Antes, nos preguntábamos si esto se vinculaba a los 15 minutos de fama que Warhol vaticinaba que todos/as íbamos a tener gracias al desarrollo tecnológico. Sin embargo, gran parte de las cuentas analizadas se mantiene en el anonimato: los/as usuarios/as con los que se registran no hacen referencia a nombres propios o a profesiones (como sí ocurre con las cuentas de algunos/as de los/as llamados/as 
influencers ${ }^{3}$ ). Tampoco hay información personal, sus avatares no son sus fotos $y$, en muchos casos, se tapan la cara cuando suben historias. ¿Será entonces que la búsqueda de fama no se centra en ser reconocidos/as ellos/as, sino en que las reconocidas sean sus obras?

Fuente: Instagram @memesdeltercermundo. Recuperada el 29/5/19

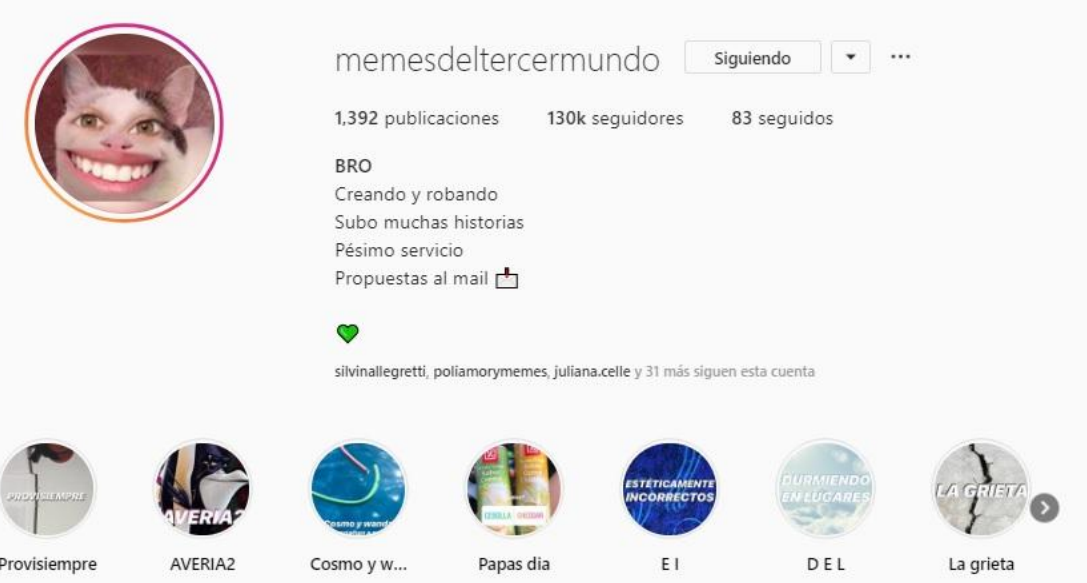

Imagen 3. Imagen de la cuenta de Instagram de @memesdeltercermundo.

Fuente: Instagram @gatitesproletaries. Recuperada el 29/5/19

( ) Instagram

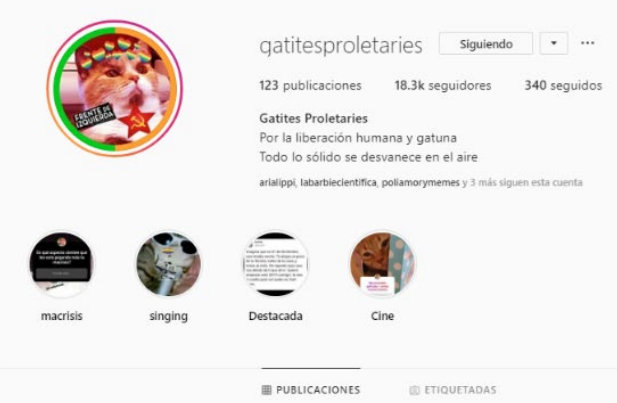

Imagen 4. Imagen de la cuenta de Instagram de @gatitesproletaries.

\footnotetext{
${ }^{3}$ Se llama "influencers" a aquellas personas que marcan tendencias en las redes sociales digitales. Generalmente tienen muchos/as seguidores/as y las temáticas de las que hablan se convierten en propagables, en tópicos de debate e intercambio que, incluso, son replicadas por los medios tradicionales (televisión, radio, revistas).
} 
Fuente: Instagram @amoxidal.duo. Recuperada el 29/5/19

๑) | Instagram

(2) $0 \circ$

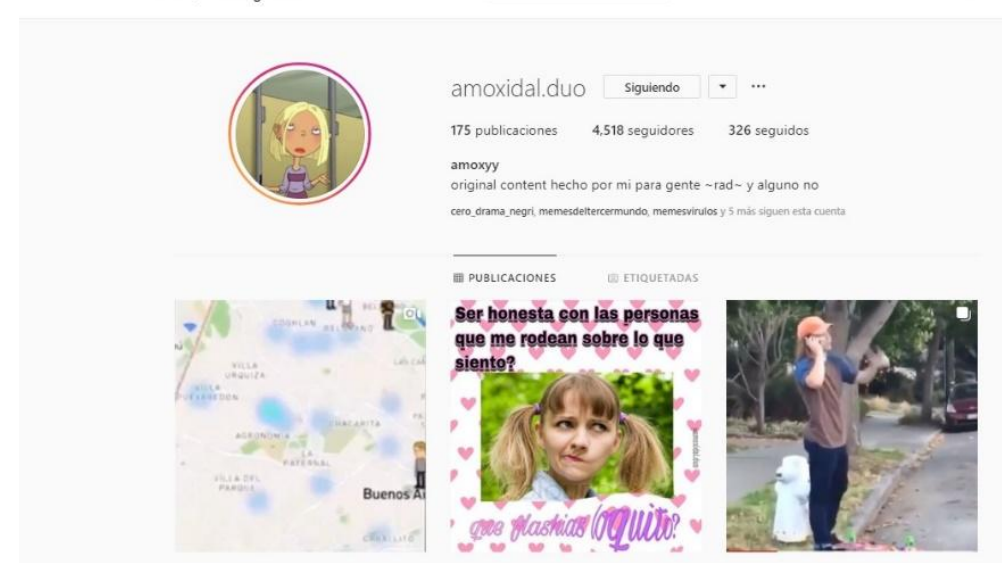

Imagen 5. Imagen de la cuenta de Instagram de @amoxidal.duo.

Fuente: Instagram @juliana.becaria. Recuperada el 9/6/2019

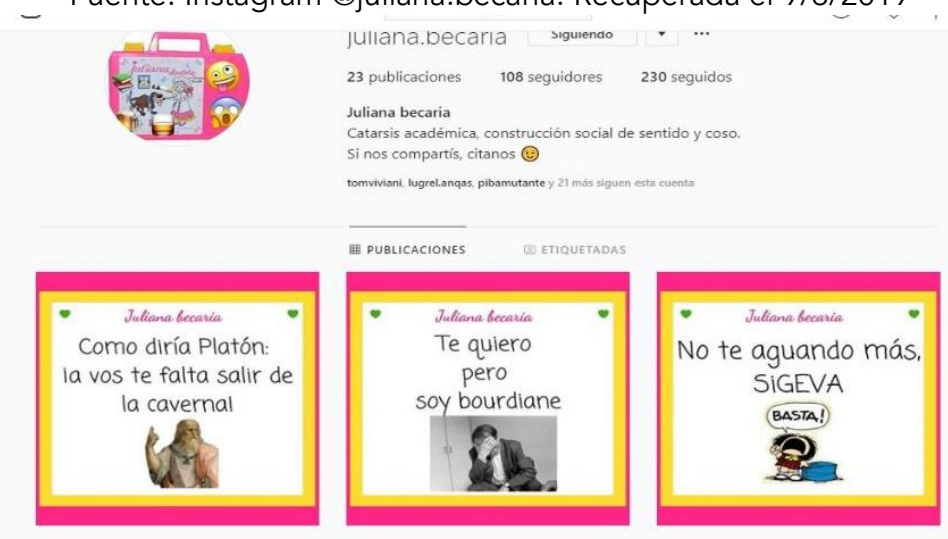

Imagen 6. Imagen de la cuenta de Instagram de @juliana.becaria.

En los ejemplos de la imagen 3, imagen 4, imagen 5 e imagen 6 vemos cómo la descripción y la imagen de perfil no remiten a marcas de identificación. Además, en los casos en que está activa la opción de "correo electrónico" la dirección a la que se vinculan tampoco ofrece datos personales. Este "anonimato" se repite en la mayoría de los casos analizados. Sin embargo, hay algunas excepciones: 
Fuente: Instagram de @tanodigennaro. Recuperada el 29/5/19

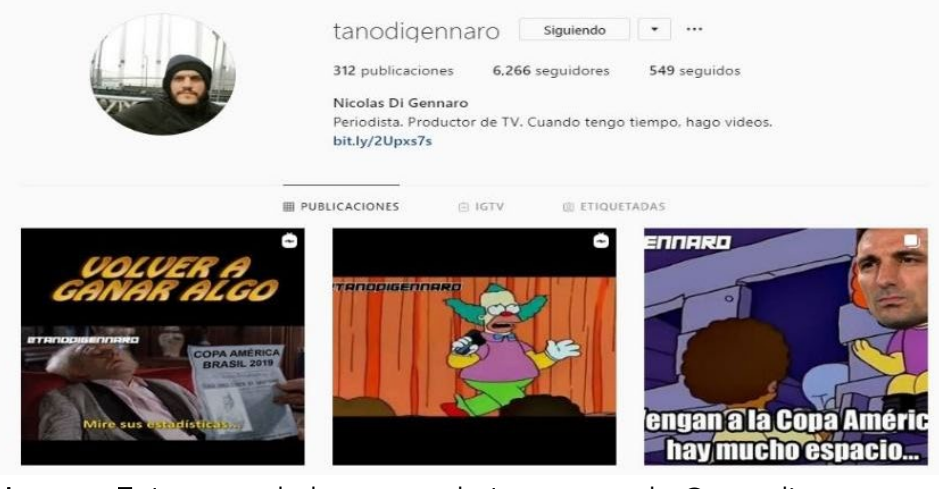

Imagen 7. Imagen de la cuenta de Instagram de @tanodigennaro.

Fuente: Instagram de @dislexical. Recuperada el 29/5/19
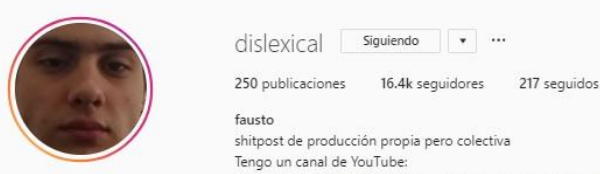

fausto

shitpost de producción propia pero colectiva

Tengo un canal de YouTube

www.youtube.com/watch?v=AIU3k8iZMj8\&feature=youtu.be

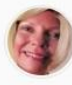

lenguaje in.

$\overline{\text { III PUBUCACIONES }}$
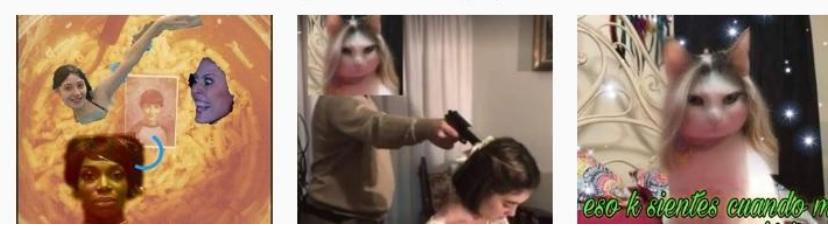

Imagen 8. Imagen de la cuenta de Instagram de @dislexical. 
Fuente: Instagram de @nose.masturben. Recuperada el 29/5/19
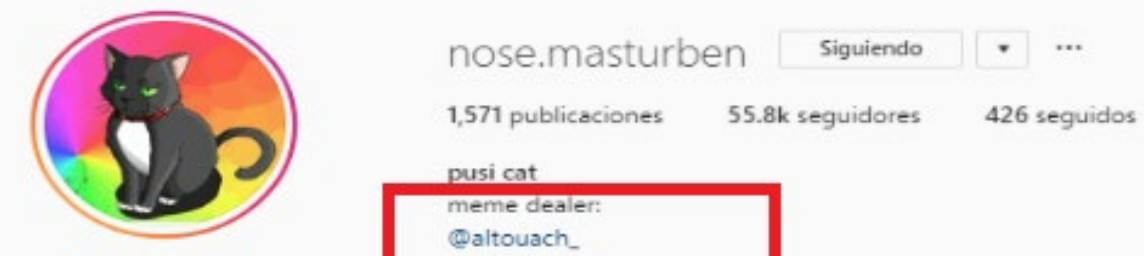

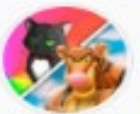

DISCORD
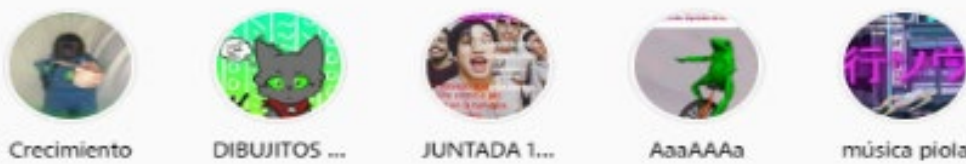

DIBUנITOS ...

JUNTADA 1...

AasAAAo

música piols

juntado

Imagen 9. Imagen de la cuenta de Instagram de @nose.masturben.

Fuente: Instagram de @mufalsa. Recuperada el 29/5/19
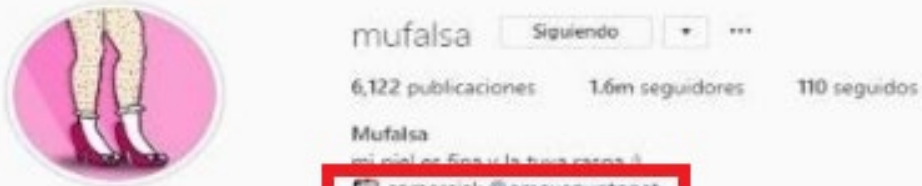

If PUEUCACIONES

Enourtana:

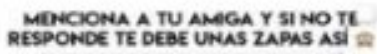

ESPONDE TE DEAE UNUS zaPAS ASI :
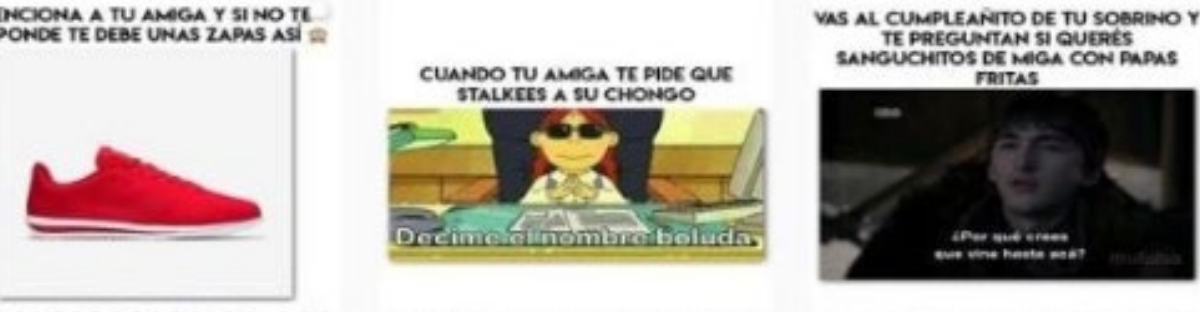

Imagen 10. Imagen de la cuenta de Instagram de @mufalsa. 
Fuente: Instagram de @memes.magicos. Recuperada el 29/5/19

(0) Instagram

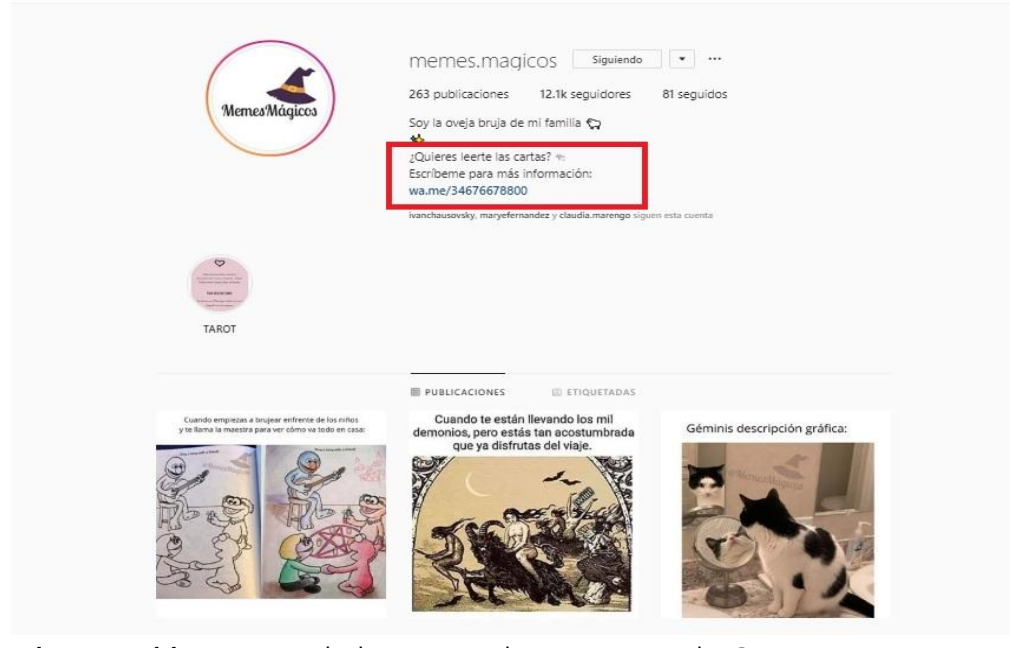

Imagen 11. Imagen de la cuenta de Instagram de @memes.magicos.

En el caso del perfil @tanodigennaro (Véase imagen 7) tanto el nombre como la foto se asocian a la persona que administra la cuenta. Además, hay un link a un canal de YouTube y una presentación que indica la profesión. En el caso de @dislexical (Véase imagen 8) la referencia no es tan clara, aparece en la foto de perfil, pero en un plano que dificulta el reconocimiento, no hay descripción personal; pero sí hay una vinculación a una cuenta de YouTube. Allí el creador del perfil @dislexical hace videos en los que se muestra abiertamente. Incluso tiene uno en el que explica cómo producir buenos memes. ${ }^{4}$

En el caso de la cuenta @nose.masturben (Véase imagen 9) aparecen las menciones a los perfiles personales de los administradores. Por su parte, la cuenta @mufalsa (Véase imagen 10) redirige a un perfil profesional de marketing, mientras que la de @memes.magicos (Véase imagen 11) pregunta "¿Quieres leerte las cartas?" y deja el link a un número de Whatsapp para solicitar esa lectura.

En estos últimos casos vemos cómo la cuenta de memes se convierte en una puerta de ingreso a una cuenta profesional, ya sea para ofrecer gestiones de marketing, consultas al tarot o derivar a los/as usuarios/as hacia sus canales de YouTube donde los contenidos se podrían monetizar. Entonces, en las prácticas de los/as usuarios/as que administran estas cuentas de memes la idea del tiempo de ocio separado del tiempo productivo se desdibuja porque sostener estas cuentas y estos contenidos no es solamente un pasatiempo, sino una proyección laboral.

${ }^{4}$ El video se puede ver en este link https://www.youtube.com/watch?v=jMz60wZ5iqA Recuperado el 29/5/2019. 


\section{Redes entre cuentas}

Una de las características identificadas al analizar estas cuentas es la colaboración que se establece entre algunas de ellas: se siguen, se citan, se recomiendan unas a otras (o algunas a algunas porque, como veremos en otro apartado, también surgen rivalidades, bandos, equipos)

Para dar cuenta de la conformación de estas redes rastreamos los vínculos que se generan entre las cuentas que respondieron la encuesta. Para esto, primero identificamos quiénes seguían a quiénes y si esa acción era recíproca. También revisamos la cantidad de "seguidores", la cantidad de cuentas que siguen y el total de publicaciones realizadas desde que fueron creadas. Respecto a este punto debemos aclarar que muchas de estas cuentas producen historias que no siempre son almacenadas bajo la categoría de "destacadas", por lo que no pueden recuperarse pasadas las 24 horas de la publicación. Por lo tanto, a veces el número de publicaciones es bajo en relación a lo esperable por la cantidad de seguidores que tienen; pero debemos considerar que son cuentas mucho más activas en la producción de historias.

La cantidad de "seguidores" y "cuentas seguidas" no es un dato menor en la lógica de visibilización que proponen las redes sociales digitales. Actualmente en Instagram estos números se han vuelto más importantes, ya que la plataforma dejó de mostrar la cantidad de "me gusta" de las publicaciones y las interacciones en las historias son privadas (entre la cuenta y el/la usuario/a que responde). En ese contexto, la cantidad de seguidores es lo que marca una distinción. La lógica de seguir a pocas cuentas demuestra una relación asimétrica y se vincula con las prácticas adoptadas por influencers: que haya una sustancial diferencia entre cuentas seguidas y seguidores.

Otro aspecto que consideramos fue la temática de los memes. Nos propusimos identificar si existía una recurrencia de temas al momento de crear o compartir memes. Luego del seguimiento de las cuentas, clasificamos esas temáticas en: Aspectos cotidianos, Estudio, Política, Responsabilidad afectiva, Historia, Feminismo/Crítica al patriarcado, Música, Videojuegos, Parapsicología, Vida de animales, Sexo y Fútbol. Dentro de la categoría "Aspectos cotidianos" incluimos los memes que abordan las actividades que se llevan a cabo en el día a día (ir al gimnasio, mirar televisión/Netflix, comer, conversar con amigos/as). Dentro de la categoría "Política" consideramos a los memes que visibilizan temas de agenda como las elecciones, el aumento de tarifas, la represión policial, las luchas salariales, el pago de la deuda, entre otros. Y también a aquellos que utilizan imágenes de figuras de la política para hacer chistes.

Las otras categorías son más específicas y se vinculan a los recorridos que tienen los/as administradores/as, por ejemplo, ser estudiantes, ser músicos, ser tarotistas. En otros casos, las temáticas están ya indicadas en los nombres de las cuentas como 
en @blessed.shitt que, predominantemente, comparte memes con contenido en el límite de lo políticamente correcto, ${ }^{5} @$ gatitesproletaries cuyos memes son políticos o @memes.free.fire.america que se vincula al juego de batalla Free Fire. ${ }^{6}$ Esta categorización no es exhaustiva y tampoco implica que las cuentas sólo publiquen ese tipo de memes sino que, durante el período de observación, fueron los tipos recurrentes. Establecer las principales temáticas abordadas por estas cuentas permite identificar un indicador de cómo se construyen las redes de vínculos.

Volcamos esta información en un cuadro de sistematización que compartimos a continuación (Véase Cuadros 1 y Cuadro 2):

Cuadro 1. Cuadro de sistematización de cuentas

\begin{tabular}{|c|c|c|c|c|c|}
\hline Cuenta & $\begin{array}{l}\text { Cantidad de } \\
\text { seguidores }\end{array}$ & $\begin{array}{l}\text { Cantidad de cuentas } \\
\text { que siguen }\end{array}$ & Cantidad de publicaciones & Temas recurrentes de los memes & $\begin{array}{l}\text { Se vinculan a otras } \\
\text { cuentas de la } \\
\text { muestra }\end{array}$ \\
\hline @amoxidal.duo & 8.225 & 465 & $\begin{array}{l}271 \text { publicaciones } \\
1 \text { historia destacada }\end{array}$ & $\begin{array}{c}\text { Estudio } \\
\text { Política } \\
\text { (Usa marcas de agua) }\end{array}$ & Sí \\
\hline @blessed.shitt & 70.998 & 542 & $\begin{array}{l}1094 \text { publicaciones } \\
2 \text { historias destacadas }\end{array}$ & $\begin{array}{l}\text { En su nombre usa la palabra "shitt" que da cuenta de } \\
\text { posteos basura. En general, humor que sería } \\
\text { considerado politicamente incorrecto. }\end{array}$ & Sí \\
\hline @chamuyicidio & 1272 & 3603 & $\begin{array}{l}37 \text { publicaciones } \\
1 \text { historia destacada }\end{array}$ & $\begin{array}{c}\text { Aspectos cotidianos } \\
\text { En muchos de sus memes utiliza imágenes de animales } \\
\text { (Usa marcas de agua) }\end{array}$ & No \\
\hline @dialectica_cumbiera & 13.519 & 159 & $\begin{array}{c}273 \text { publicaciones } \\
\text { No hay historias destacadas }\end{array}$ & $\begin{array}{l}\text { Aspectos cotidianos } \\
\text { Política } \\
\text { (Usa marcas de agua) }\end{array}$ & Sí \\
\hline @dislexical & 15.284 & 940 & $\begin{array}{c}71 \text { publicaciones } \\
2 \text { historias destacadas }\end{array}$ & Responsabilidad afectiva & Sí \\
\hline @el_restaurador77 & 33.920 & 106 & $\begin{array}{l}387 \text { publicaciones } \\
24 \text { historias destacadas }\end{array}$ & $\begin{array}{l}\text { Política (desde la perspectiva peronista) } \\
\text { Historia/ Vida de Juan Manuel de Rosas } \\
\text { (Usa marcas de agua) }\end{array}$ & Sí \\
\hline @elalesicumbiaok & 445.945 & 206 & $\begin{array}{l}1961 \text { publicaciones } \\
1 \text { historia destacada }\end{array}$ & $\begin{array}{l}\text { Aspectos cotidianos } \\
\text { Política }\end{array}$ & Sí \\
\hline @elconejitotincho & 44.359 & 334 & $\begin{array}{l}114 \text { publicaciones } \\
16 \text { historias destacadas }\end{array}$ & $\begin{array}{c}\text { Feminismo } \\
\text { Crítica al patriarcado }\end{array}$ & Sí \\
\hline @fachawaveok & 51.341 & 624 & $\begin{array}{l}1158 \text { publicaciones } \\
4 \text { historias destacadas }\end{array}$ & $\begin{array}{l}\text { Aspectos cotidianos } \\
\text { (Usa marcas de agua) }\end{array}$ & Sí \\
\hline @faketalesofmattty & 26.946 & 471 & $\begin{array}{l}1340 \text { publicaciones } \\
38 \text { historias destacadas }\end{array}$ & $\begin{array}{l}\text { Aspectos cotidianos } \\
\text { Utiliza imágenes de animé } \\
\text { (Usa marcas de agua) }\end{array}$ & Sí \\
\hline @gatitesproletaries & 34.519 & 441 & $\begin{array}{l}247 \text { publicaciones } \\
2 \text { historias destacadas }\end{array}$ & $\begin{array}{l}\text { Política (desde la postura de la izquierda) } \\
\text { Usa imágenes de gatos }\end{array}$ & Sí \\
\hline @gringowave666 & 5095 & 1605 & $\begin{array}{l}594 \text { publicaciones } \\
13 \text { historias destacadas }\end{array}$ & Música/Bandas & Sí \\
\hline
\end{tabular}

En amarillo se resaltan dos cuentas que son administradas por la misma persona

Fuente: Elaboración propia. Fecha de toma de los datos 16-2-20

\footnotetext{
${ }^{5}$ En Internet "shitt" remite a contenido basura.

${ }^{6}$ Free Fire es un videojuego de batalla que se puede jugar en red y desde diferentes dispositivos. El objetivo es sobrevivir a enfrentamientos entre escuadrones. Tiene diferentes versiones y se puede jugar de manera individual o colectiva.
} 
Cuadro 2. Cuadro de sistematización de cuentas

\begin{tabular}{|c|c|c|c|c|c|}
\hline Cuenta & $\begin{array}{l}\text { Cantidad de } \\
\text { seguidores }\end{array}$ & $\begin{array}{l}\text { Cantidad de cuentas } \\
\text { que siguen }\end{array}$ & Cantidad de publicaciones & Temas recurrentes de los memes & $\begin{array}{l}\text { Se vinculan a otras } \\
\text { cuentas de la } \\
\text { muestra }\end{array}$ \\
\hline @juliana.becaria & 116 & 239 & $\begin{array}{l}25 \text { publicaciones } \\
\text { No hay historias destacadas }\end{array}$ & $\begin{array}{l}\text { Estudio } \\
\text { (Usa marcas de agua. No comparte memes más allá de } \\
\text { los que producen con una estética definida) }\end{array}$ & No \\
\hline @lonely.ass.niggas & 24.483 & 97 & $\begin{array}{c}596 \text { publicaciones } \\
3 \text { historias destacadas }\end{array}$ & $\begin{array}{l}\text { Aspectos cotidianos } \\
\text { Política } \\
\text { (Usa marca de agua) }\end{array}$ & sí \\
\hline @memelobeibi & 2.323 & 987 & $\begin{array}{l}238 \text { publicaciones } \\
6 \text { historias destacadas }\end{array}$ & $\begin{array}{l}\text { Aspectos cotidianos } \\
\text { (Usa marca de agua) }\end{array}$ & Sí \\
\hline @memes.free.fire.america & 103.412 & 155 & $\begin{array}{l}1008 \text { publicaciones } \\
4 \text { historias destacadas }\end{array}$ & Videojuegos & No \\
\hline @memes.magicos & 36.441 & 140 & $\begin{array}{l}386 \text { publicaciones } \\
1 \text { historia destacada }\end{array}$ & $\begin{array}{c}\text { Parapsicología } \\
\text { (Usa marcas de agua) }\end{array}$ & No \\
\hline @memesdeltercermundo & 207.570 & 103 & $\begin{array}{l}1429 \text { publicaciones } \\
42 \text { historias destacadas }\end{array}$ & $\begin{array}{c}\text { Aspectos cotidianos } \\
\text { Vida de animales (Gatos) } \\
\text { Feminismo } \\
\text { Estudio }\end{array}$ & sí \\
\hline @memesmarcacuenta & 39.279 & 586 & $\begin{array}{l}1169 \text { publicaciones } \\
\text { No hay historias destacadas }\end{array}$ & Aspectos cotidianos & Sí \\
\hline @mufalsa & 2.001 .025 & 666 & $\begin{array}{l}8907 \text { publicaciones } \\
\text { No hay historias destacadas }\end{array}$ & $\begin{array}{l}\text { Aspectos cotidianos } \\
\text { (Usa marca de agua) }\end{array}$ & No \\
\hline @nose.masturben & 106000 & 548 & $\begin{array}{c}2262 \text { publicaciones } \\
7 \text { historias destacadas }\end{array}$ & $\begin{array}{l}\text { Aspectos cotidianos } \\
\text { Política } \\
\text { Sexo }\end{array}$ & Sí \\
\hline $\begin{array}{l}@ \text { @nzneca } \\
@ \text { n3necaa* }\end{array}$ & $\begin{array}{l}193.000 \\
11.770\end{array}$ & $\begin{array}{l}500 \\
16\end{array}$ & $\begin{array}{l}\text { 7o publicaciones } \\
1 \text { historia destacada }\end{array}$ & $\begin{array}{l}\text { Feminismo/Crítica al patriarcado } \\
\text { Sexo }\end{array}$ & Si \\
\hline @poxyram & 111.631 & 397 & $\begin{array}{l}584 \text { publicaciones } \\
\text { No hay historias destacadas }\end{array}$ & $\begin{array}{l}\text { Aspectos cotidianos } \\
\text { (Usa marca de agua) }\end{array}$ & sí \\
\hline @resu.memes & 1514 & 353 & $\begin{array}{l}391 \text { publicaciones } \\
\text { No hay historias destacadas }\end{array}$ & $\begin{array}{l}\text { Aspectos cotidianos } \\
\text { Fútbol } \\
\text { Política }\end{array}$ & No \\
\hline @tanodigennaro & 17101 & 645 & $\begin{array}{l}424 \text { publicaciones } \\
3 \text { historias destacadas }\end{array}$ & $\begin{array}{c}\text { Fútbol } \\
\text { Utiliza generalmente imágenes de Los Simpsons } \\
\text { (Usa marcas de agua) }\end{array}$ & No \\
\hline
\end{tabular}

Fuente: Elaboración propia- Fecha de toma de los datos $16-2-20^{7}$

De este relevamiento se desprende que sólo 7 de las cuentas seguidas no han establecido vínculos con otras cuentas de la muestra analizada y esto coincide con cierta especificidad temática de los memes: parapsicología, música y videojuegos. Pero también hay cuentas como @mufalsa que, pese a trabajar memes de la categoría más extendida -"Aspectos cotidianos"- tampoco se vincula con otras de las cuentas de la muestra. Luego del seguimiento realizado, podemos sostener que tiene que ver con que se dedica al marketing y a la publicidad, por lo que sus intereses de construir redes pasan por otro tipo de cuentas, por ejemplo, marcas de ropas, empresas de decoración, comercios.

Por su parte, cuentas como la de @memesdeltercermundo, @elconejitotincho y @dislexical, que abordan aspectos como el feminismo, la crítica al patriarcado o la responsabilidad afectiva, se repostean los memes en las historias, se citan y se comentan. También siguen y son seguidas por otras cuentas que abordan temas políticos como @lonely.ass.nigas, @dialectica_cumbiera, @amoxidal.duo,

\footnotetext{
${ }^{7}$ Figuran dos nombres para @n3neca porque su cuenta "original" de Instagram - @n3neca - fue cerrada y debió abrir una nueva en enero de 2020. Además, en algunos momentos de 2019 también utilizó @neneca69 porque su otra cuenta fue denunciada en distintas oportunidades.
} 
@elalesicumbiaok. (Véase imagen 12, imagen 13, imagen 14, imagen 15 e imagen 16)

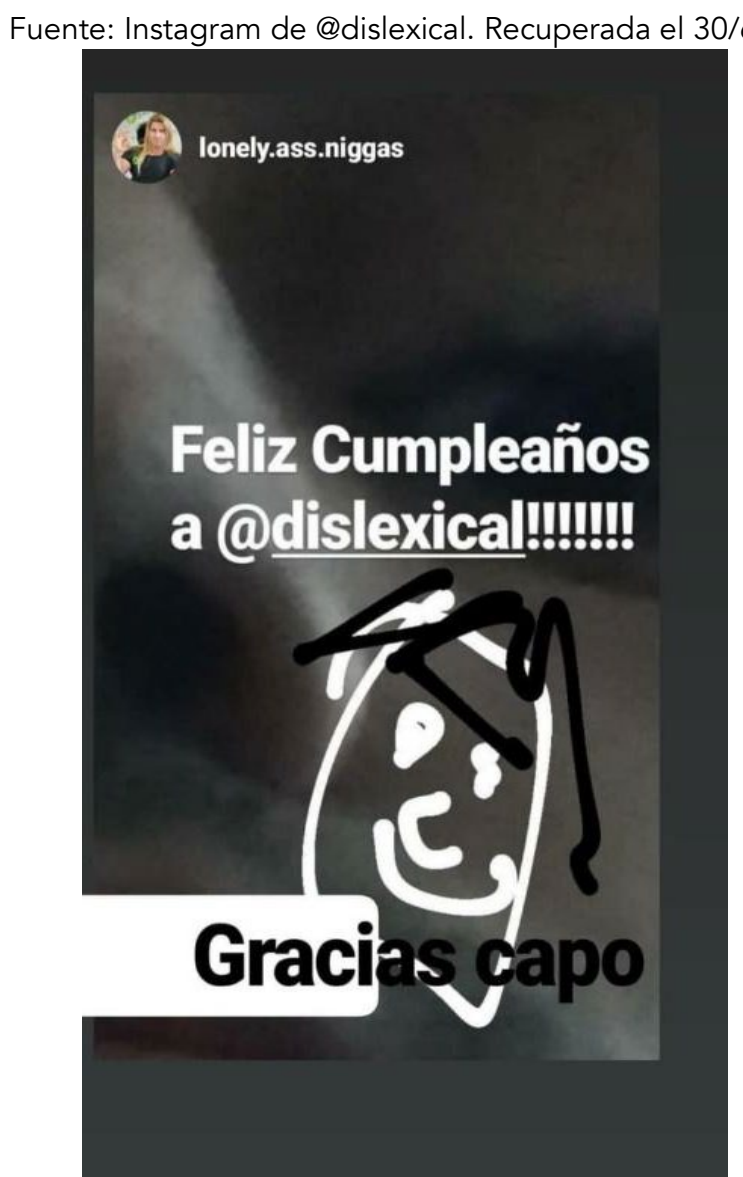

Imagen 12. Historia de la cuenta de @dislexical agradeciéndole a @lonely.ass.niggas un saludo de cumpleaños. 
- Bianca Racioppe, Julieta Párraga

Fuente: Instagram de @amoxidal.duo. Recuperada el 30/6/19

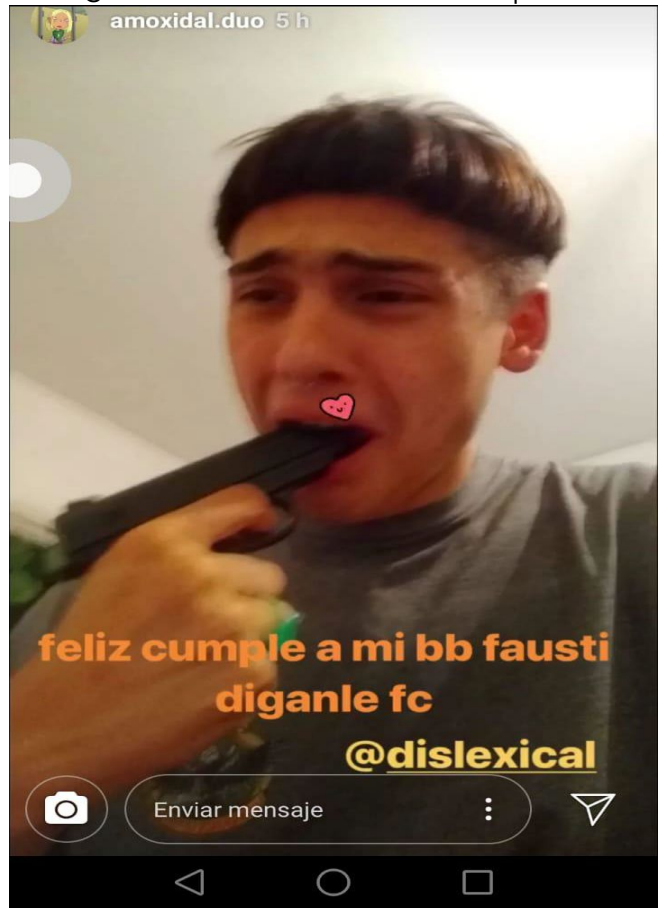

Imagen 13. Historia de la cuenta de @amoxidal.duo en la que saluda a @dislexical por su cumpleaños.

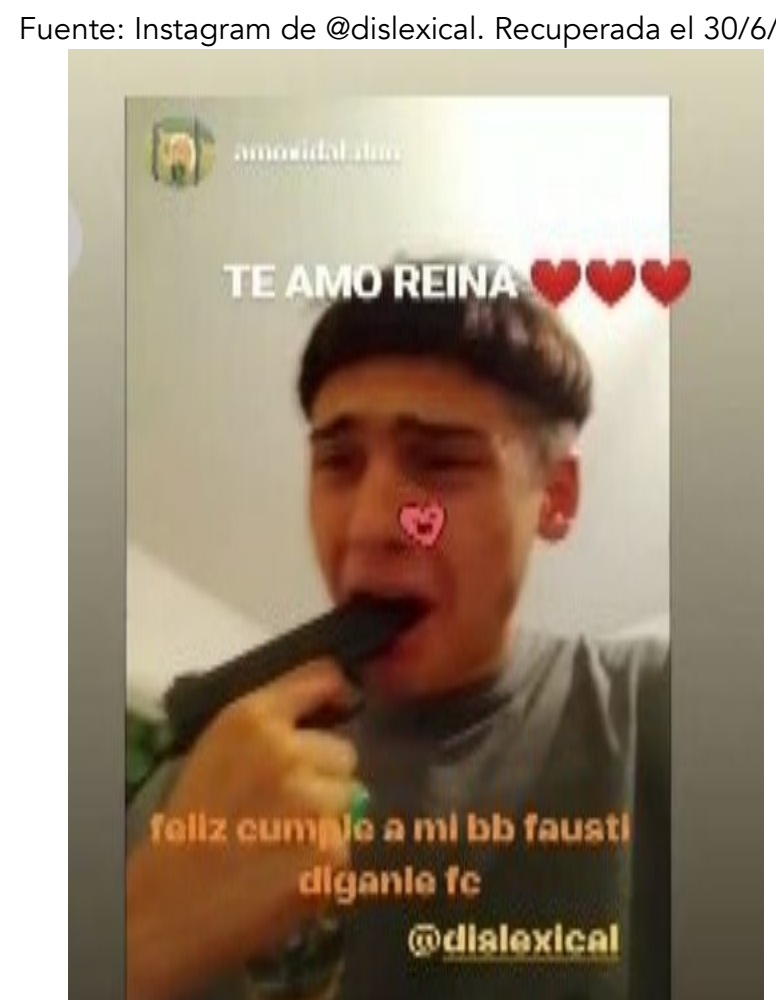

Imagen 14. Historia de la cuenta de @dislexical en la que le contesta a @amoxidal.duo. 
Fuente: Instagram de @elconejitotincho. Recuperada el 30/6/19

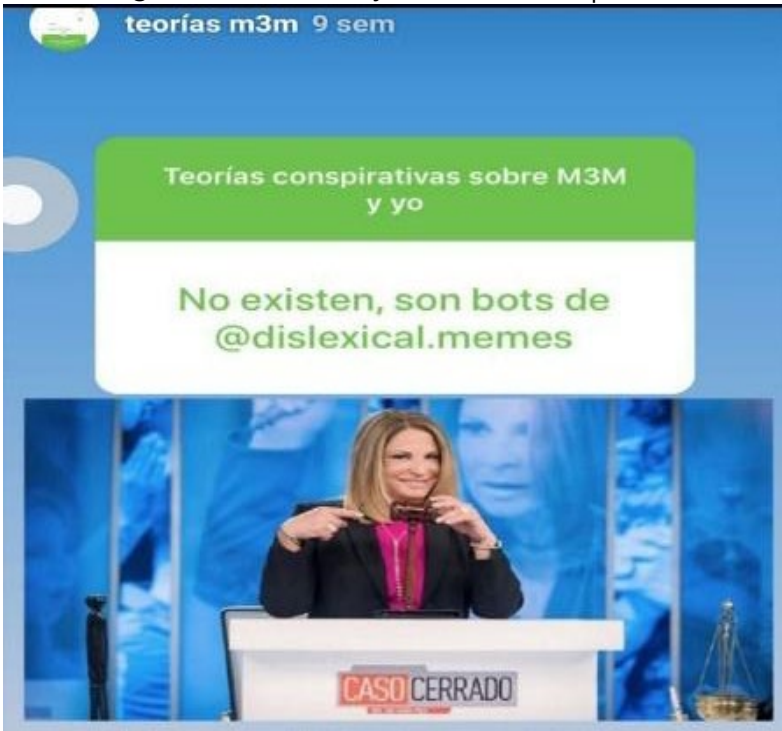

(a) dislexicalinemes comments?

Imagen 15. Historia de la cuenta de @elconejitotincho que nombra a @memesdeltercermundo y a @dislexical. 
Fuente: Instagram de @dialectica_cumbiera. Recuperado el 30/6/19

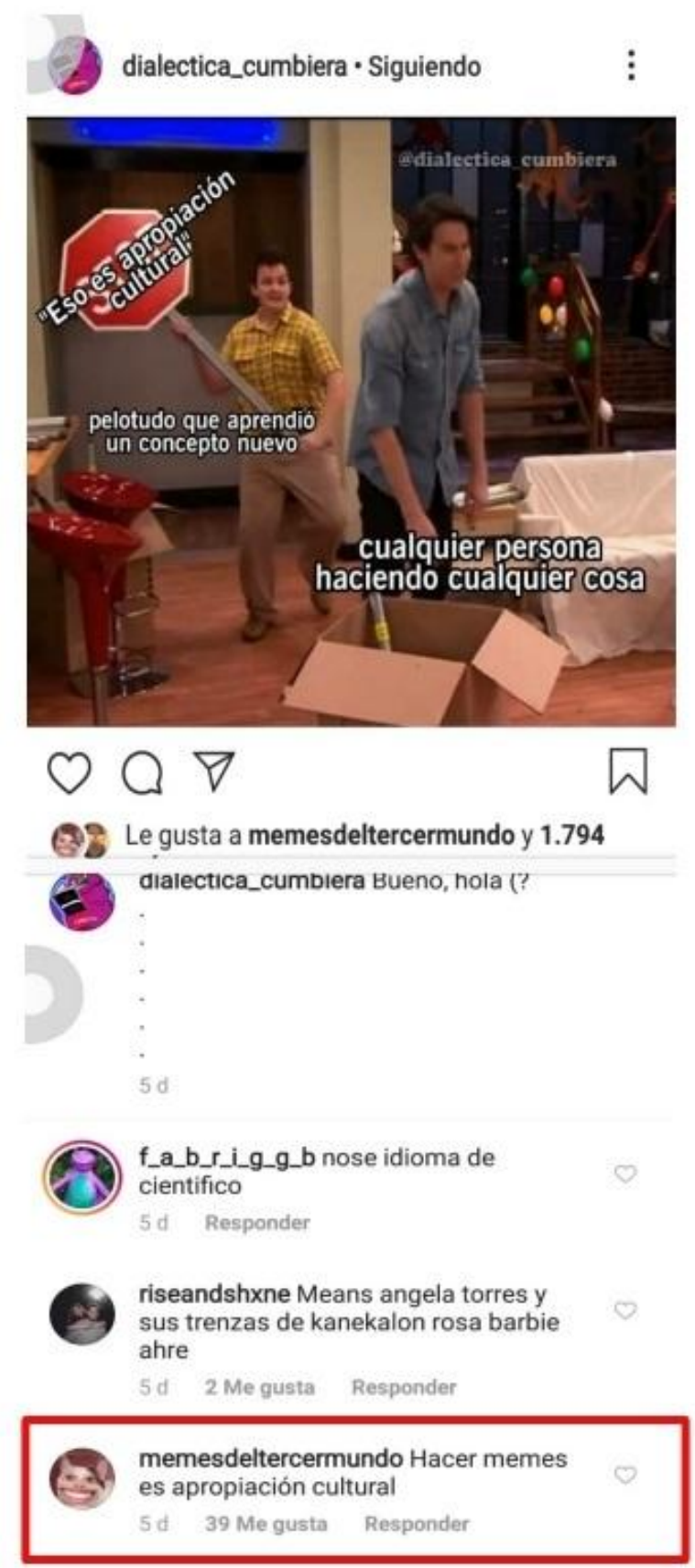

Imagen 16. Posteo de @dialectica_cumbiera en el que @memesdeltercermundo hace un comentario.

En estas capturas vemos esas relaciones que planteábamos antes. Los saludos a @dislexical por su cumpleaños (Véanse imágenes 12, 13 y 14) al igual que la historia 
de @elconejitotincho (que abre un juego con los/as seguidores/as para que planteen teorías respecto de su relación con @memesdeltercermundo) (Véase imagen 15) pueden indicar que también hay una relación que va más allá del espacio de las redes sociales digitales. Este aspecto, el de las redes en lo offline que nutren las redes en lo online, deberá profundizarse en otros momentos de la investigación.

Además, el seguimiento de estas cuentas y la sistematización de los temas que abordan permite preguntarse por las relaciones que se dan a partir de los modos de hacer humor y, especialmente, cuando estos modos están ligados al feminismo. Otro aspecto a profundizar en próximas etapas de la investigación es la grupalidad que se genera entre cuentas administradas por jóvenes feministas como @memesdeltercermundo, @elconejitotincho y @n3neca. ${ }^{8}$

\section{Memes, copias y Copyright}

Unas páginas más arriba nos preguntábamos por el anonimato y postulábamos la hipótesis de que el no mostrarse en las redes podría relacionarse con el hecho de que se busca principalmente una propagación del producto y no necesariamente de la persona que lo produce. Podría pensarse que las autorías no tienen relevancia para los/as administradores/as de estas cuentas; sin embargo, sólo unos/as pocos/as han señalado abiertamente que no creen en la propiedad autoral. Nos enfrentamos, así, no sólo a las restricciones que imponen las grandes industrias culturales, sino también a las lógicas capitalistas de la competencia que se reproducen incluso en estos espacios aparentemente anónimos y desvinculados de toda pretensión de fama o rédito económico.

En ese sentido, observamos que muchas cuentas utilizan marcas de agua para señalar los memes que han creado, es decir escriben sobre las imágenes o videos el nombre de su cuenta de tal modo que, si el meme circula, quede registro de quién lo creó. Contrario a esto, sólo 4 de las cuentas de la muestra señalaron que indagan si los materiales que utilizan están sujetos a Copyright. Esto pone en evidencia una lógica bastante extendida respecto de la apropiación de los bienes simbólicos en la que al momento de buscar materiales se considera que lo que circula por Internet es de uso común; mientras que luego se restringe, se marca, aquello que se produjo con esos recursos.

Durante el seguimiento de las cuentas se identificaron dos modos de copia en la lógica de producción de memes: uno aceptado que consiste en la derivación y la resignificación, y otro que es denunciado por considerarlo deshonroso. En el primer

\footnotetext{
${ }^{8}$ Si bien la cuenta @n3neca no respondió la encuesta se incluyó en el seguimiento porque es una de las memeras que puede considerarse influencer. Además de su cuenta en Instagram tiene una cuenta en Twitter y ha dado entrevistas en revistas, podcast y programas de radio.
} 
grupo encontramos casos en que una imagen es utilizada en reiteradas ocasiones, pero con diferentes sentidos (Véase imagen 17). De hecho, se generan modas en el uso de ciertas imágenes a las que se le otorgan diferentes significados, pero que se basan en una estructura similar.

Fuente: Instagram de @dislexical y @elalesicumbiaok. Recuperadas el 12/6/19
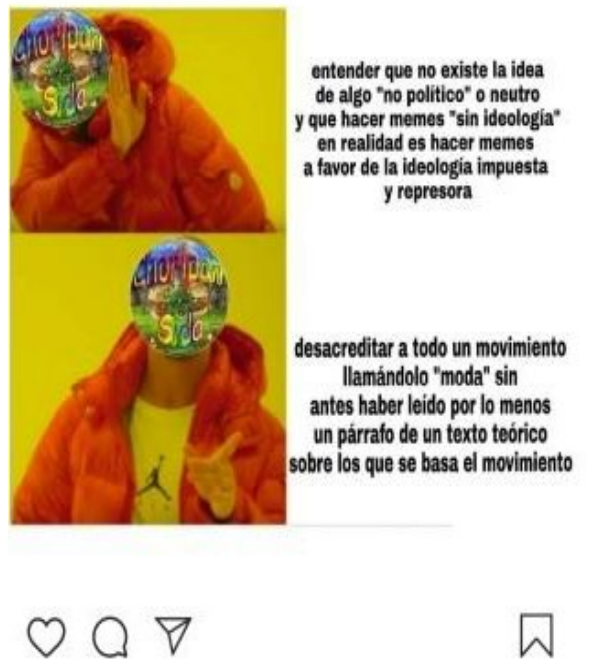

\section{Me gusta}

dislexical.memes Hola no sé quién es choripan y sida ni me interesa, pero si sé que hay mucha gente que piensa como él, que los memes tienen que ser "neutros", osea tibios, no los banco en esa, ni ahi, adios

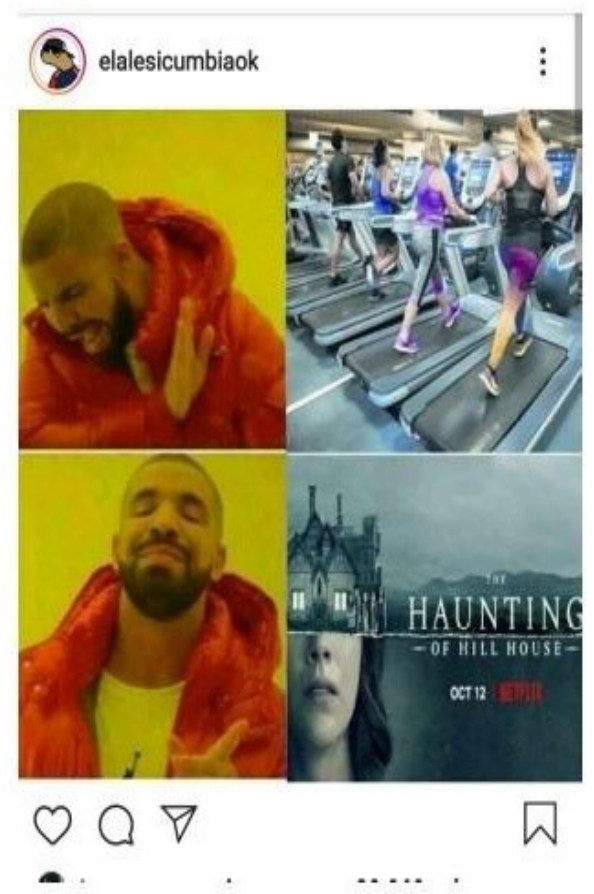

Imagen 17. Imágenes de las cuentas de Instagram de @dislexical y @elalesicumbiaok.

En estos casos no hay crítica a la reutilización de las imágenes porque el meme varía de acuerdo a las combinaciones que hace cada creador/a. El conflicto aparece cuando se reproduce, no sólo cierta combinación de imágenes, sino el contenido en su totalidad. Es decir, cuando el meme exacto es puesto en circulación por otra cuenta sin hacer la correspondiente referencia a la autoría original. En este sentido se han identificado casos en que los/as seguidores/as denuncian el uso de los memes por otras cuentas (Véase imagen 18 e imagen 19). 
Fuente: Twitter de @lilapau. Recuperadas el 27/02/2019

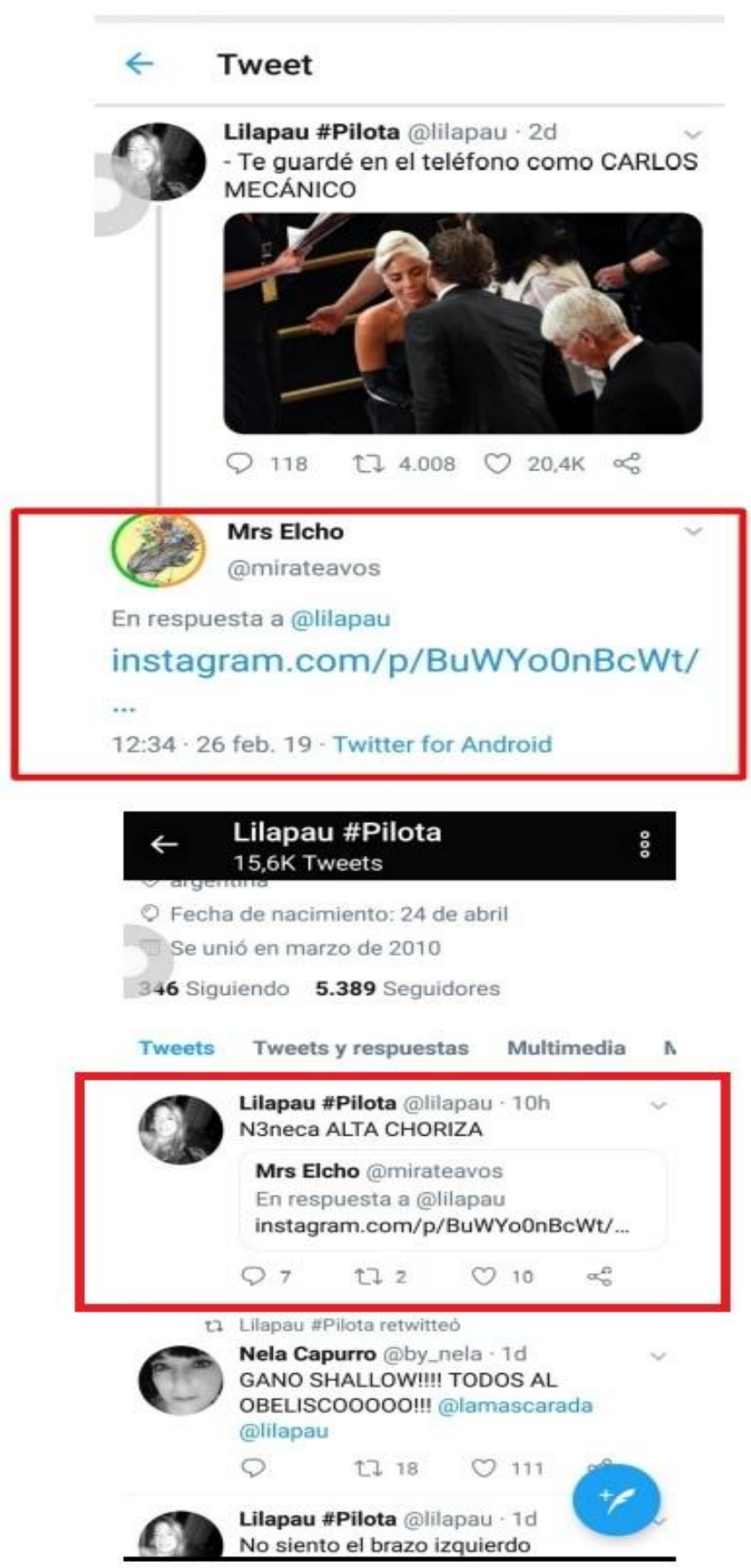

Imagen 18. Imágenes de la cuenta de Twitter de @|ilapau. 
Fuente: Instagram de @n3neca. Recuperada el 11/06/2019
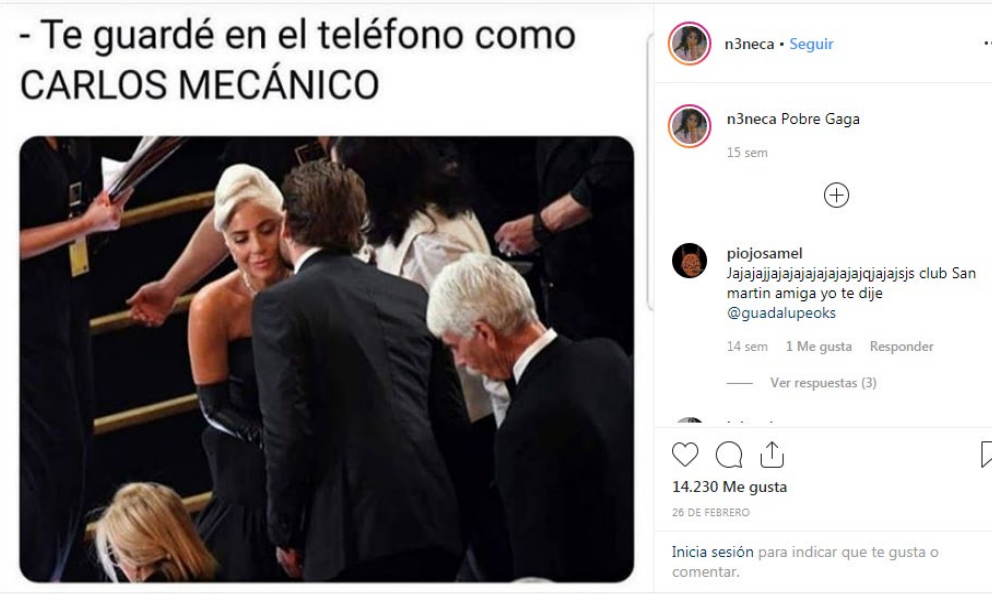

Imagen 19. Imagen de la cuenta de Instagram de @n3neca.

En este ejemplo, la cuenta de Twitter de @lilapau es advertida por la de @mirateavos acerca del uso que hace @n3neca de un meme que había posteado primero @lilapau. De paso, además de advertir a la otra cuenta, @mirateavos se queja de que le pasa lo mismo (Véase imagen 20):

Fuente: Twitter de @mirateavos. Recuperada el 11/6/2019

Mrs Elcho@mirateavos·26 feb.

En respuesta a @lilapau

Mal. Banda de memes que salen de acá, aparecen ahí al día siguiente sin mención o créditos:

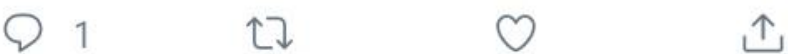

Imagen 20. Imagen de la cuenta de Twitter de @mirateavos.

@n3neca les responde definiéndolos como haters (odiadores/as) (Véase imagen 21). En las redes sociales digitales cuando se logra cierta cantidad de seguidores/as y, por lo tanto, un estatus de influencer, también se obtienen haters. La primera cuenta de @n3neca -que fue reportada y cerrada por Instagram- tenía 193 mil seguidores/as y ella sólo seguía a 500 cuentas (porque seguir a pocos es, como ya se señaló, una marca de distinción) ${ }^{9}$ Con esta historia @n3neca convierte la acusación en algo que la beneficia en la competencia por la visibilidad y el reconocimiento. No cualquiera tiene haters.

\footnotetext{
9 @lilapau tiene 6 mil seguidores/as en Twitter y sigue a 400 (datos recabados el 16/2/20) La cuenta de Mrs Elcho@mirateavos, en cambio, no tiene muchos/as seguidores/as (70 al 16/2/20) y sigue a 144 cuentas de Twitter. (Datos recuperados el 16/2/20)
} 
Fuente: Instagram de @n3neca. Recuperada el 27/2/2019

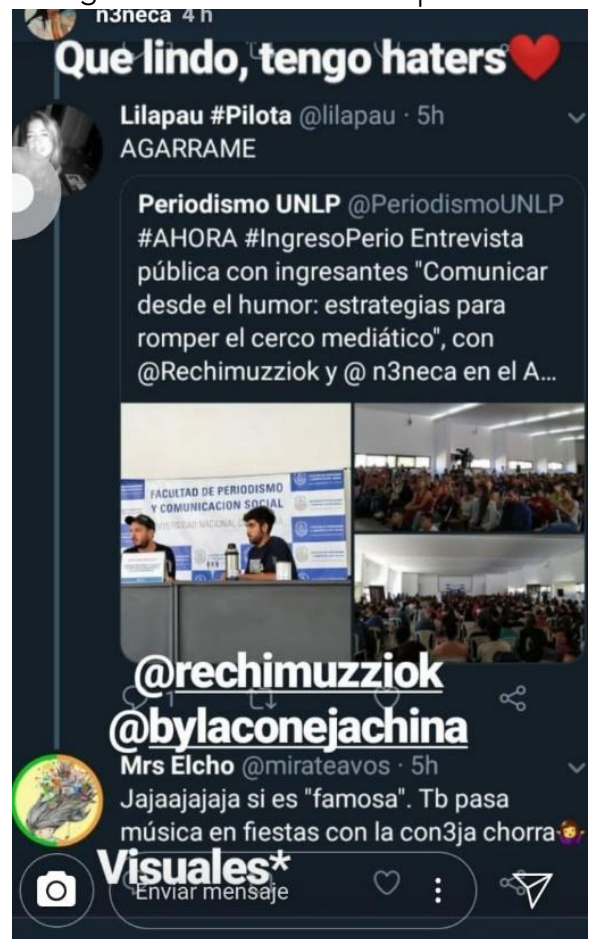

Imagen 21. Historia de la cuenta de Instagram de @n3neca.

En un video del canal de YouTube de Paulina Roca (más conocida como Paulina Cocina), @n3neca se refiere a los derechos de los contenidos que produce y dice: "(...) no creo en la marca de agua, no creo en 'este contenido es mío', para mí los memes son el folklore de Internet. (...) Hay muchas cosas que las saco, me las pasan, pero no existe el robar en el meme. Mucha gente me bardea diariamente por no poner quién me lo pasó y no, es de todes." (Roca, 2019) 
Fuente: Instagram de @blessed.shitt. Recuperado el 24/4/19
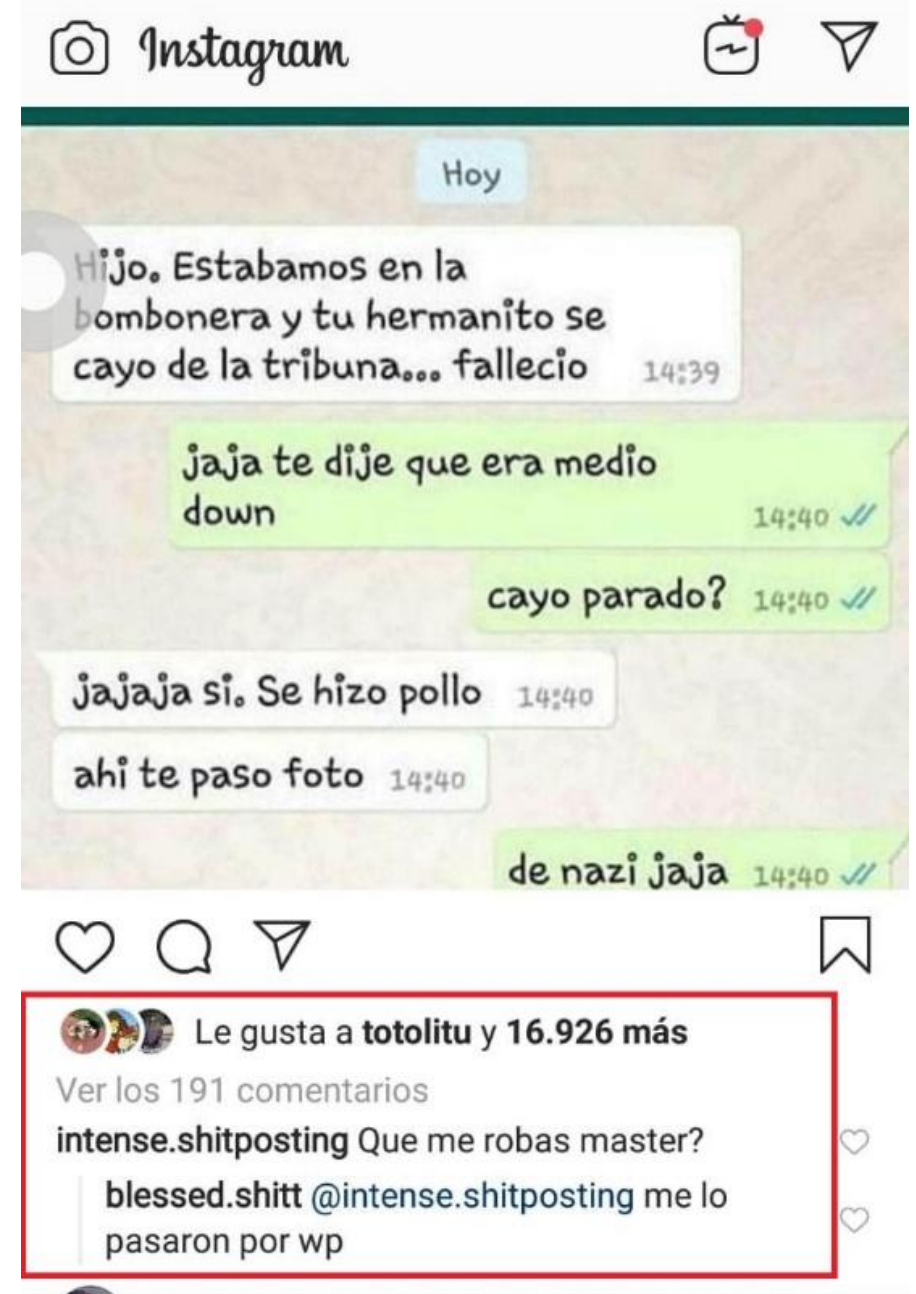

Imagen 22. Posteo del Instagram de @blessed.shitt.

En este otro ejemplo se utiliza un tipo de meme que se basa en supuestas conversaciones por Whatsapp (Véase imagen 22). El chiste es discriminatorio y ofensivo (por ejemplo la referencia al síndrome de down como juego de palabras con "go down" que es "caer" en inglés); pero lo que queremos señalar es el comentario que hace un usuario acusando a la cuenta de @blessed.shitt de haberle robado el material y la respuesta acerca de la procedencia: "me lo pasaron por wp". En esta conversación aparecen dos temas que entran en tensión: la pelea por las propiedades de los contenidos y la lógica de circulación de los memes que implica la propagación sin referencia a orígenes o a fuentes.

Ese tipo de circulación donde las autorías se desdibujan se potencia en la digitalidad por la gran propagación que puede alcanzar un contenido; sin embargo, y tal como lo explica García Huerta (2014: 5), este tipo de narrativas se emparentan con los grafitis y con los esténciles que se hacen en las paredes de los territorios 
offline, pero que también se copian, se derivan y circulan, muchas veces, sin registros de autorías.

En el caso de los memes, vemos que la misma comunidad actúa como censora que alerta de "robos" y, como suele ocurrir en estos espacios, se generan "bandos", grupos que apoyan a uno/a u otro/a. La discusión que se da es interesante porque, contrariamente a lo que señalábamos en el apartado anterior en relación a la colaboración, en este caso aparece la competencia y la pelea por las propiedades y las citas, requisitos de territorios que no son los de los memes que, justamente, se basan en la circulación y en la propagación sin referencia de orígenes. Por lo tanto, estas cuentas de memes, en la disputa por seguidores/as, pretenden establecer propiedades de materiales que antes circulaban sin que las autorías fueran importantes.

Otros/as usuarios/as, en cambio, comprenden la dinámica de la circulación de los memes en Internet y ya en su enunciación se refieren a la copia (Véase imagen 23).

Fuente: Instagram de @memesdeltercermundo. Recuperada el 24/4/19
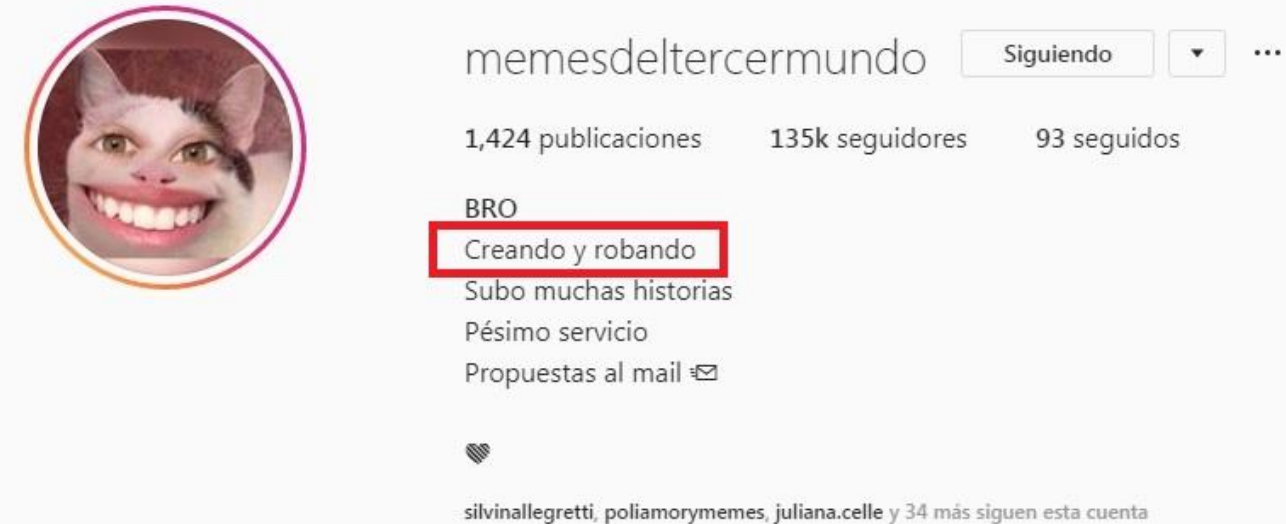

Imagen 23. Imagen de la cuenta de Instagram de @memesdeltercermundo.

@memesdeltercermundo define sus acciones como "creando y robando" y en las respuestas de la encuesta aclaró que los memes que comparte son en algunos casos creados por ella; pero también compartidos de otras cuentas. Este tipo de respuesta se dio en 12 de los 23 casos, los otros 11 sostuvieron que los memes que comparten en sus cuentas los crean ellos/as. Sin embargo, cuando responden en relación a los materiales que usan para construir esos memes (imágenes, videos, textos) surge que los obtienen de bancos de Internet. Tampoco muestran una preocupación por conocer si esos recursos que usan están sujetos a Copyright, sólo 4 de las cuentas que respondieron la encuesta explicaron que indagan en las propiedades de los materiales que usan, 5 manifestaron que lo han hecho en 
algunos casos, pero no siempre; mientras que las 14 cuentas restantes contestaron que no se preocupan por averiguar eso.

Más allá de esta falta de preocupación por el Copyright, algunas cuentas han tenido problemas por el uso de música y de videos que fueron reconocidos por los algoritmos de Instagram como materiales con derechos registrados. Esta identificación por parte de los bots conlleva la baja de la publicación. "Hace poco hice una parodia de un capítulo de Los Simpson con el gol de Maradona a los ingleses. Cuando lo subí a Instagram me lo bajaron por usar los derechos de la serie" explica @tanodigennaro. En varias de las respuestas a la encuesta aparece el problema de la sanción por parte de Instagram frente al uso de música o videos con Copyright.

Esta denuncia, ya no por parte de los/as seguidores/as, sino de las plataformas, se vincula a que Instagram, Facebook, YouTube son intermediarios que adhieren a las reglamentaciones de las grandes industrias culturales que detentan los derechos de circulación de canciones, películas, marcas o personajes. Si bien el uso que se hace de estos materiales entraría dentro de lo que se denomina uso legítimo, por ejemplo, la parodia; los robots encargados de controlar el Copyright no distinguen esto y tratan a estos memes como si fueran productos pirateados.

\section{El vil metal: la monetización de los proyectos}

Si bien, como mencionábamos antes, la mayoría de las personas encuestadas señalaron que la creación de memes es principalmente un pasatiempo, algunas de ellas explicaron que esas cuentas les permiten cobrar visibilidad para promocionar otras de sus actividades. A partir de las observaciones que realizamos podemos describir que la rentabilidad o monetización de algunos de estos proyectos se genera a partir de la publicidad y el canje. Debido a que estas cuentas de Instagram tienen muchos/as seguidores/as, las marcas les realizan ofertas para hacer publicidad a cambio de productos, servicios o dinero.

En el caso de la cuenta de Instagram @memes.magicos en la descripción de la misma la administradora del perfil ofrece realizar lecturas de tarot (Véase imagen 24). En nuestra encuesta contestó: "Hacer memes me permite además de difundir información, promocionar mis servicios, creo que son una gran herramienta". 
Fuente: Instagram de @memes.magicos. Recuperada el 29/5/2019

(0) Instagram

a Buscar

(2) $\bigcirc \circ$
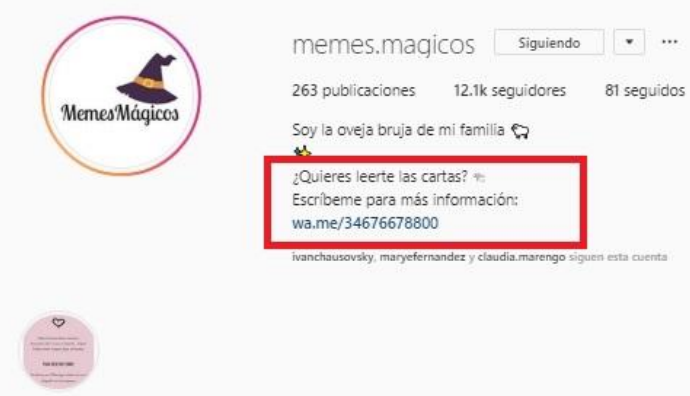

TAROT
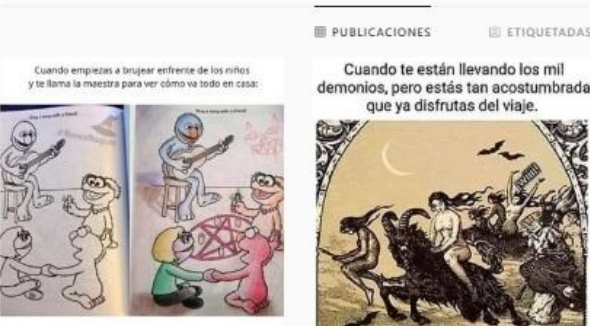

Cuando te están llevando los mil

demonios, pero estás tan acostum

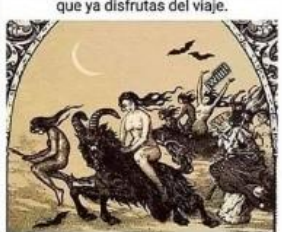

Géminis descripción gráfica:

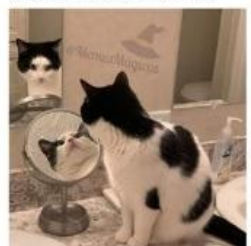

Imagen 24. Imagen de la cuenta de Instagram de @memes.magicos.

Otra de las cuentas que indagamos fue la de @mufalsa, que está compuesta por un grupo de productores de marketing. En este perfil observamos que hay publicaciones que mantienen la lógica narrativa del meme y, a su vez, contienen publicidad de manera implícita. También nos encontramos con publicaciones que, lejos de tener alguna lógica vinculada al humor, publicitan productos y marcas (Véase imagen 25). 


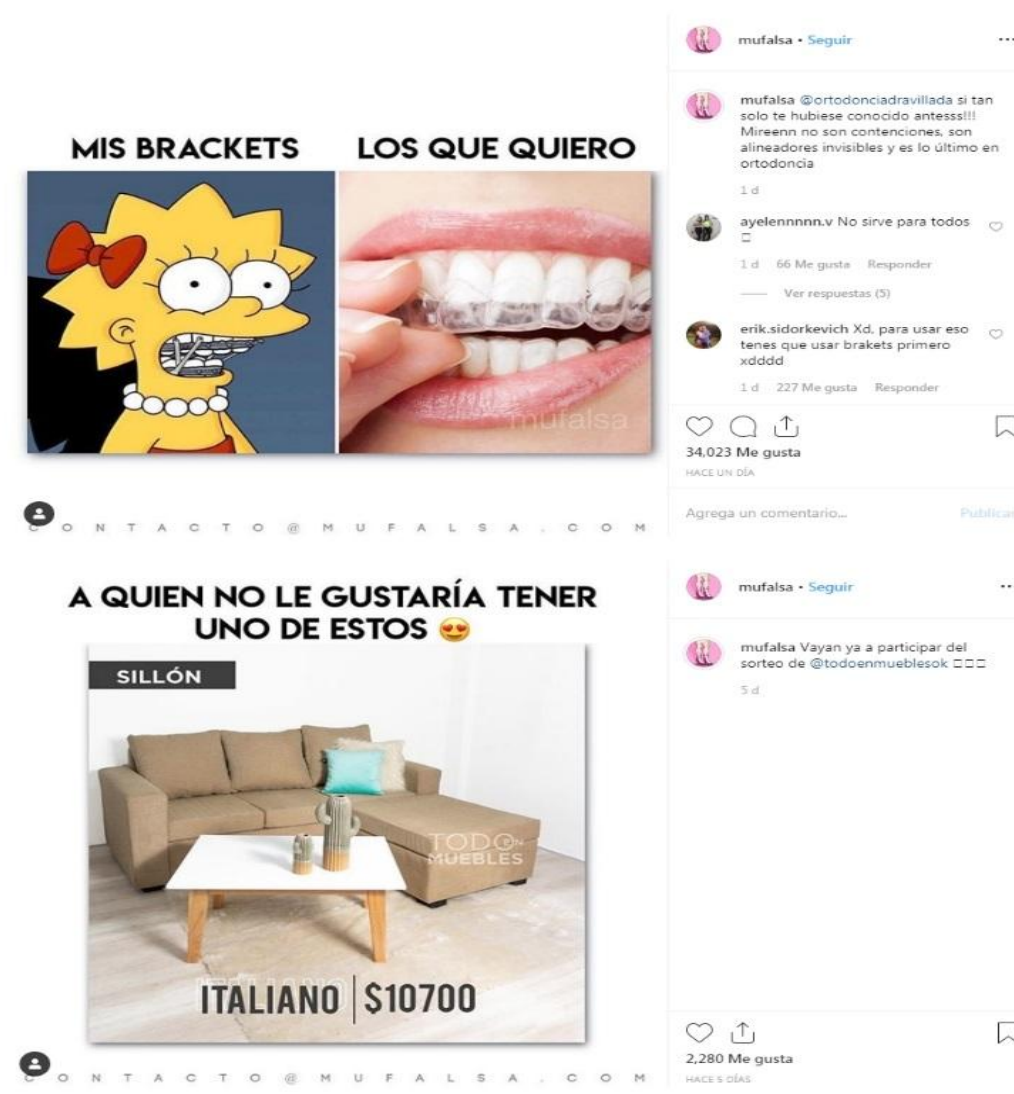

Imagen 25. Imágenes del Instagram de @mufalsa.

Las redes sociales digitales, salvo YouTube, no retribuyen económicamente a sus usuarios/as por los contenidos que realizan. Por este motivo las estrategias de monetización se basan en vínculos e intercambios entre los/as productores/as y las marcas.

En otras ocasiones, las redes sociales digitales funcionan como plataformas de visibilización de diversas actividades que luego les permiten ser contratados/as por empresas o productoras más grandes. En estos casos Instagram actúa como vidriera. Esta práctica es frecuente en las lógicas de cuentas de profesionales que brindan información y hacen divulgación en redes sociales digitales para potenciar otros proyectos que se dan en lo offline: publicación de libros, charlas, talleres (Racioppe, Párraga y Bruzzone, 2018).

\section{Conclusiones}

Este artículo se vincula a una investigación más amplia que tiene como objetivo principal identificar y analizar narrativas, estéticas y políticas en el escenario de la 
convergencia tecnológica. En el marco de ese proyecto, el meme es una de las narrativas que hemos identificado como recurrente en los espacios digitales.

Estos primeros datos recolectados a partir de la encuesta y de la etnografía virtual permiten identificar algunos nudos de análisis que deberán profundizarse en el desarrollo de la investigación.

En primer lugar, el artículo explora motivaciones y expectativas que permiten conocer a los/as productores/as y no sólo a sus materiales. La pregunta acerca de los momentos destinados a la producción de los memes nos da una pauta respecto de cómo entienden al trabajo y al ocio. Al mismo tiempo, las respuestas sobre las expectativas nos colocan en otra perspectiva porque, aunque las cuentas de meme se crean "para divertirse", "para pasar el rato", "como un hobby"; también aparece un deseo de proyección hacia un trabajo remunerado en espacios digitales. Esto no necesariamente quiere decir que pretenden vivir de hacer memes; sino que expresan su deseo de trabajar en la realización de contenidos para Internet. De hecho, algunas cuentas ya usan los memes como forma de interpelación para luego visibilizar otros proyectos.

Como se puede ver en los memes que se compartieron a lo largo de este artículo, un aspecto interesante es el uso y resignificación que se hace de distintos recursos como las imágenes, los videos, las capturas de Whatsapp que, acompañados de textos y viñetas, adquieren distintos sentidos. Se interpela desde el humor, desde la ironía para destacar situaciones cotidianas. Desde algunas cuentas señalaron, incluso, que pretenden informar de otra manera y generar una contracultura. Esto se da en los casos de cuentas con una clara postura ideológica como @elconejitotincho (que combate la mirada patriarcal) o @gatitesproletaries (que busca reflexiones políticas desde el humor). Es decir que el meme no sólo se produce y comparte para obtener "me gusta" y seguidores/as, sino que también invita a reírse de situaciones cotidianas, genera identificación y, en algunos casos, pretende reflexiones críticas.

En este punto uno de los aspectos a profundizar en la investigación es la conformación de grupos y comunidades de memeros/as que se vinculan a través de un estilo de humor y por compartir miradas de mundo; por ejemplo, las memeras feministas.

En relación a la circulación de los memes, este análisis nos permitió reconocer que en estos modos que se presentan como novedosos persisten valores asociados a la distribución analógica; por ejemplo, la preocupación por las referencias, por las autorías y por los usos que hacen los/as otros/as de los materiales. Esto entra en tensión con unas formas de producción que, en muy pocos casos, indagan respecto de los derechos que podrían tener las imágenes, videos y canciones que utilizan. La idea de la propiedad privada, propia de la matriz liberal, aparece en las prácticas de circulación de los memes cuya producción, paradójicamente, se caracteriza por 
la reutilización y el collage. Es un aspecto interesante para continuar indagando acerca de cómo las lógicas de las grandes industrias culturales han permeado en nuestros modos de comprender lo cultural-artístico.

Por último, el artículo explora los modos de monetizar estas prácticas. Este aspecto se vincula también a las concepciones de las redes sociales digitales como lugares de ocio, de tiempo libre y sin densidad suficiente para ser consideradas espacios de trabajo. Sin embargo, esta exploración nos permitió reconocer ciertas experiencias en las que las cuentas de memes son una especie de vidriera para otras actividades, como los servicios de marketing. Además, debemos considerar que plataformas como YouTube nos muestran la posibilidad de profesionalizar las producciones que circulan en Internet, creadas por sujetos no insertos en las grandes productoras de contenidos. Cuando nos referimos a profesionalización no hablamos de calidad, sino de la posibilidad de que los/as creadores/as puedan vivir de esto. Un debate que atraviesa al campo estético desde antes del desarrollo de Internet y que ahora cobra nueva visibilidad en las culturas digitales. 


\section{Referencias bibliográficas}

BOURRIAUD, N. (2007): Postproducción. La cultura como escenario: modos en que el arte reprograma el mundo contemporáneo. Adriana Hidalgo: Buenos Aires.

BÜRGER, P. (2000): Teoría de la vanguardia. Ediciones Península: Barcelona (3a edición)

CARRIER, E. (2019): Radiografía de redes, Informe de Carrier y Asociados. Disponible en:

https://comentarios.info/index.php/2019/08/02/radiografia-de-redes/

CHIARENZA, D. (2019): En comunicación el orden de los factores sí altera el resultado Disponible en: https://www.instagram.com/p/Bw5fcr2Hvls/

DAWKINS, R. (1989): El gen egoísta. Las bases biológicas de nuestra conducta (Segunda edición). Disponible en:

http://biologia.utalca.cl/wp-content/uploads/2018/01/El-Gen-Egoista.pdf

GARCÍA, D. (2014): Las imágenes macro y los memes de internet: posibilidades de estudio desde las teorías de la comunicación. Paakat: Revista de Tecnología y Sociedad, 4 (6). Disponible en:

http://www.udgvirtual.udg.mx/paakat/index.php/paakat/article/view/217/317

GIMPEL, J. (1979): Contra el arte y los artistas. O el surgimiento de una religión. Gedisa: Barcelona.

HINE, C. (2004): Etnografía Virtual. Editorial UOC: Barcelona.

HOOTSUITE y WE ARE SOCIAL (2019): Digital 2019 Argentina. Disponible en: https://datareportal.com/reports/digital-2019-argentina?rq=Argentina

JENKINS, H. (2008): Convergence Culture. La cultura de la convergencia de los medios de comunicación. Paidós: Barcelona.

JENKINS, H., FORD, S. y GREEN, J. (2015): Cultura transmedia. La creación de contenido y valor en una cultura en red. Gedisa: Barcelona.

KOZINETS, R. (2010): Netnography: Doing Ethnographic Research Online. Sage: Londres.

MARTín-BARBERO, J. (1991) De los medios a las mediaciones. Comunicación, cultura y hegemonía. Gustavo Gili: México (Segunda Edición). 
MATTELART, A. (1996): La comunicación-mundo. Historia de las ideas y de las estrategias. Siglo XXI: Madrid.

MCLUHAN, M. (1996): Comprender los medios de comunicación. Las extensiones del ser humano. Paidós: Buenos Aires.

PÉREZ, G. (2017): El meme en Internet. Identidad y usos sociales. Universidad Autónoma de Coahuila: México.

RACIOPPE, B., PÁRRAGA, J. y BRUZZONE, D. (2018): Narrativas en Internet. El caso de influencers en Instagram y YouTube: entre el Mercado y las hegemonías alternativas. Ponencia presentada al III COMCIS-II CCP. Facultad de Periodismo y Comunicación Social, UNLP. Disponible en:

https://perio.un/p.edu.ar/ojs/index.php/actas

RINCÓN, O. (2006): Narrativas mediáticas. O cómo se cuenta la sociedad del entretenimiento. Gedisa: Barcelona.

(2017): Pensar el entretenimiento: discursos y mutaciones de la cultura del espectáculo. [Tesis de doctorado] Universidad Nacional de Colombia: Bogotá. Disponible en:

http://bdigital.unal.edu.co/61325/1/19430458.2017.PENSAR\%20el\%20entretenim iento\%20-\%200mar\%20RINCON\%20-\%20\%20\%28Tesis\%20doctoral\%20CES\%29 .pdf

ROCA, P. (2019): La mesa de Paulina \#02: El Demente, Jorge Te Lo Resumo, Merakio, Inutilísimas, Cande Sánchez, Neneca. Disponoble en: https://www.youtube. com/watch?v=mSYcct802Z8\&t=3420s

SCHMUCLER, H. (1984): Un proyecto de Comunicación/Cultura. Revista Comunicación y Cultura. Disponible en:

https://comunicacionlvm.files.wordpress.com/2015/11/h-schmucler-un-proyectode-comunicacion-cultura.pdf

SCOLARI, C. (2008): Hipermediaciones. Elementos para una Teoría de la Comunicación Digital Interactiva. Gedisa: Barcelona.

(2010): Ecología de los medios. Mapa de un nicho teórico. Quaderns del CAC, 34 , vol. XIII.

SILVERSTONE, R. (2004): ¿Por qué estudiar los medios? Amorrortu: Buenos Aires.

THOMPSON, J. B. (1998): Los medios y la modernidad. Una teoría de los medios de comunicación. Paidós: Barcelona.

THORNTON, S. (2009): Siete días en el mundo del arte. Edhasa: Barcelona. 
VALERI, A. (2019): Cara a cara: N3neca. Revista digital ADM. Disponible en: https://agendademusica.com/2019/03/cara-a-cara-n3neca/

WILLIAMS, R. (1992): Tecnologías de la comunicación e instituciones sociales en Williams, R. (ed.) Historia de la comunicación vol. 2. Bosch: Barcelona.

(2011): Televisión, tecnología y forma cultural. Paidós: Buenos Aires. 


\section{ANEXO \\ Cuentas de memes analizadas}

@amoxidal.duo https://www.instagram.com/amoxidal.duo/ @blessed.shitt https://www.instagram.com/blessed.shitt/ @chamuyicidio https://www.instagram.com/chamuyicidio/ @dialectica_cumbiera https://www.instagram.com/dialectica_cumbiera/ @dislexical https://www.instagram.com/dislexical/ @El_Restaurador77 https://www.instagram.com/el_restaurador77/ @elalesicumbiaok https://www.instagram.com/elalesicumbiaok/ @elconejitotincho https://www.instagram.com/elconejitotincho/ @faketalesofmattty https://www.instagram.com/faketalesofmattty/ @gatitesproletaries https://www.instagram.com/gatitesproletaries/ @gringowave666 - @fachawaveok https://www.instagram.com/fachawaveok/ https://www.instagram.com/gringowave666/

@juliana.becaria https://www.instagram.com/juliana.becaria/ @lonely.ass.niggas https://www.instagram.com/_lonely.ass.niggas/ @memelobeibi https://www.instagram.com/memelobeibi/?hl=es-la @memes.free.fire.america https://www.instagram.com/memes.free.fire.america/ @memes.magicos https://www.instagram.com/memes.magicos/ @memesdeltercermundo https://www.instagram.com/memesdeltercermundo @memesmarcacuenta https://www.instagram.com/memesmarcacuenta/ @mufalsa https://www.instagram.com/mufalsa/ @nose.masturben https://www.instagram.com/nose.masturben/ @n3neca / @neneca69 / @n3necaa https://www.instagram.com/n3necaa/?hl=es-la (Si bien no contestó la encuesta, utilizamos su cuenta para el análisis) @poxyram https://www.instagram.com/poxyram/ @resu.memes https://www.instagram.com/resu.memes/ @tanodigennaro https://www.instagram.com/tanodigennaro/ 